\title{
Detection of ErbB2: nanotechnological solutions for clinical diagnostics
}

\author{
Omar K. Mahfoud, ${ }^{\text {a }}$ Tatsiana Y. Rakovich, ${ }^{\text {a }}$ Adriele Prina-Mello, ${ }^{\text {ab }}$ Dania Movia, ${ }^{b}$ \\ Frauke Alves ${ }^{c}$ and Yuri Volkov ${ }^{\text {ab }}$
}

\begin{abstract}
Clinically, overexpression of human epidermal growth factor receptor 2 (ErbB2) is considered to be an important hallmark for a number of solitary and metastatic cancers, and has been approved as a drug treatment target for ErbB2-positive cancers. Additionally, the soluble cleaved form of ErbB2 protein (sErbB2), found in blood, has been shown to be a valuable marker for tumour diagnosis in ErbB2-positive breast cancer. Although a variety of clinical diagnostic approaches have been developed to establish ErbB2 load, they each have their own pitfalls. Nanotechnology has offered some promising breakthrough solutions towards imaging and quantifying ErbB2 at the molecular level and holds the possibility of improving the sensitivity and reliability of ErbB2 detection for clinical purposes. Here we review the currently available methods of ErbB2 detection and quantification in biological samples, followed by analysis and evaluation of those nanotechnological approaches which have demonstrated most potential to improve clinical diagnostic practises.
\end{abstract}

Received 26th September 2013 Accepted 18th November 2013

DOI: 10.1039/c3ra45401k

www.rsc.org/advances intrinsic tyrosine kinase activity and growth factor receptor function. ErbB2 is a receptor tyrosine kinase that belongs to the ErbB or EGFR (epidermal growth factor receptor) family (Fig. 1). The ErbB2 receptor shows basal expression in many tissue types and is involved in normal tissue development and function, such as in the heart. ${ }^{1}$ Signalling through the ErbB2 receptor occurs following receptor dimerisation with the other ErbB family receptors or with another ErbB2 receptor itself. Such receptor dimerisation promotes cell growth and division, thus causing uncontrolled cell proliferation and hence tumour formation when overexpressed. Additionally, activation of the

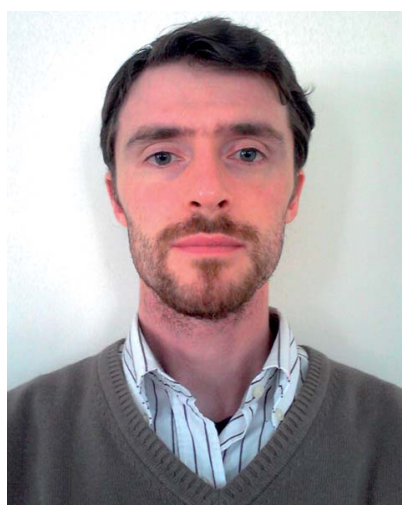

Omar Mahfoud graduated from Trinity College Dublin in 2008 with a degree in Neuroscience. He is currently undertaking his PhD studies in the Nanomedicine and Molecular Imaging Group in the Department of Clinical Medicine at Trinity College. He is involved in an EU FP7-funded project (NAMDIATREAM) aimed at developing the next generation of nanomaterial-based diagnostic systems for the advanced detection of breast, lung and prostate cancer biomarkers. Previous to this he completed his MSc Molecular Medicine in University Medical Centre Göttingen on development of human stem cell and human iPSC differentiation strategies for their cultivation to neuronal fates.

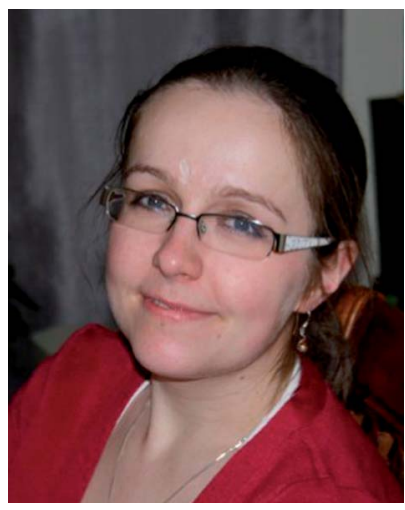

Dr. Tatsiana Rakovich is a potdoctoral research fellow in Prof. Yuri Volkov's group, Department of Clinical Medicine, Trinity College Dublin. Her current research forms part of the NAMDIATREAM project, funded under the $E U 7^{\text {th }}$ Framework Platform. One of the aims of this project is the development of nanotechnology for early detection and imaging of molecular biomarkers of the three most common cancer types, such as lung, breast and prostate, as well as for a lower threshold identification of the onset of early-stage malignancies with the use of innovative technology, such as "labon-a-bead" and "lab-on-a-wire" nano-devices. 
ErbB2 signalling pathways leads to an increase of tumour metastasis-associated properties (such as invasion and angiogenesis) and induces therapeutic resistance via receptor-mediated anti-apoptotic signals. ${ }^{2}$

\subsection{Clinical importance of ErbB2 detection: focus on breast cancer}

Since the mid-1980s, overexpression of the ErbB2 protein has been recognised as a feature of a malignant cancerous phenotype in breast cancer cell lines ${ }^{4,5}$ and has become one of the most widely investigated clinical indicators used to assess the severity of breast, ovarian, gastrointestinal and lung cancers ${ }^{6-9}$ and guide targeted therapies. ${ }^{10}$ Most of the focus around ErbB2 oncogenic function has been centred on its role in breast cancer. This is probably because breast cancer is by far the most commonly occurring form of cancer in women, accounting for $23 \%$ of total cancer incidences and contributing to nearly $14 \%$ of the cancer-related mortality. ${ }^{\mathbf{1 1}}$ The incidences of breast cancers are much higher in more developed regions (e.g. Western Europe) compared to less developed regions (e.g. Eastern Africa), whereas the mortality rate associated with breast cancer progression is similar between different world regions (Fig. 2).

There are four major molecular subtypes in breast cancer which are classified based on the expression profiles of three receptors (Table 1): ${ }^{12,13}$ luminal A (estrogen receptor (ER) and/or progesterone receptor (PR) positive, ErbB2 negative), luminal B (ER and/or PR positive, ErbB2 positive), basal-like (ER negative, PR negative, ErbB2 negative) and ErbB2 (ER negative, PR negative, ErbB2 positive).

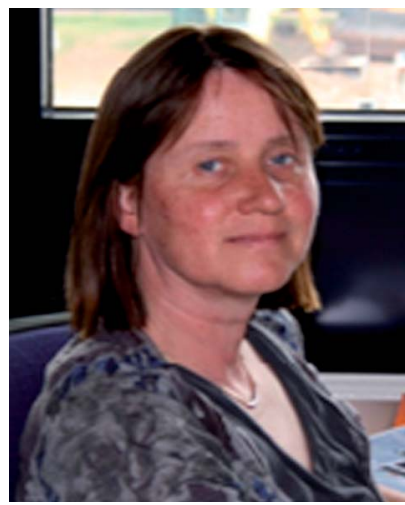

Prof. Frauke Alves has a long standing track record in basic research and preclinical evaluation of tumor diagnostic tools and tumor therapies by applying molecular imaging techniques. She heads a research group in the Dept. of Hematology and Oncology at the University Medicine Center, Göttingen. Since 2008, she leads a second research group at the MaxPlanck-Institute for Experimental Medicine in Göttingen, in the Dept. of Molecular Biology of Neuronal Signals. The focus of her interdisciplinary and translational molecular imaging group is the investigation of mechanisms of tumour progression and the development of novel diagnostic tools in combination with fluorescent nanoprobes.

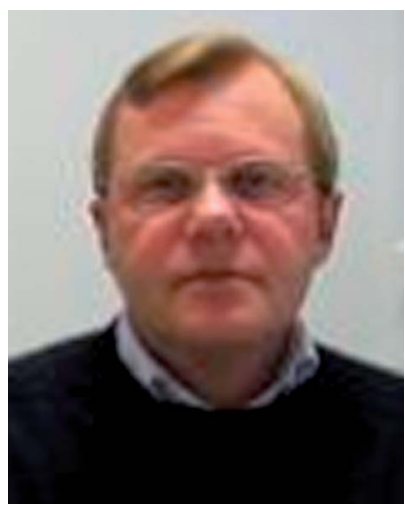

Prof. Yuri Volkov received his MD from the Moscow Medical University and subsequently a $P h D$ in biomedical sciences, Institute of Immunology, Moscow. He is a Professor at the Department of Clinical Medicine and the Director of Research of the School of Medicine at Trinity College Dublin. Prof. Volkov coordinates a large-scale EU FP-7 NAMDIATREAM project with 22 European academic, research, clinical and industrial partners for early diagnostics and monitoring of malignant diseases. He is also a lead TCD partner for the EU FP-7 MULTIFUN project and principal investigator in many grants. Prof. Volkov has published more than 80 articles, several patents and book chapters. 


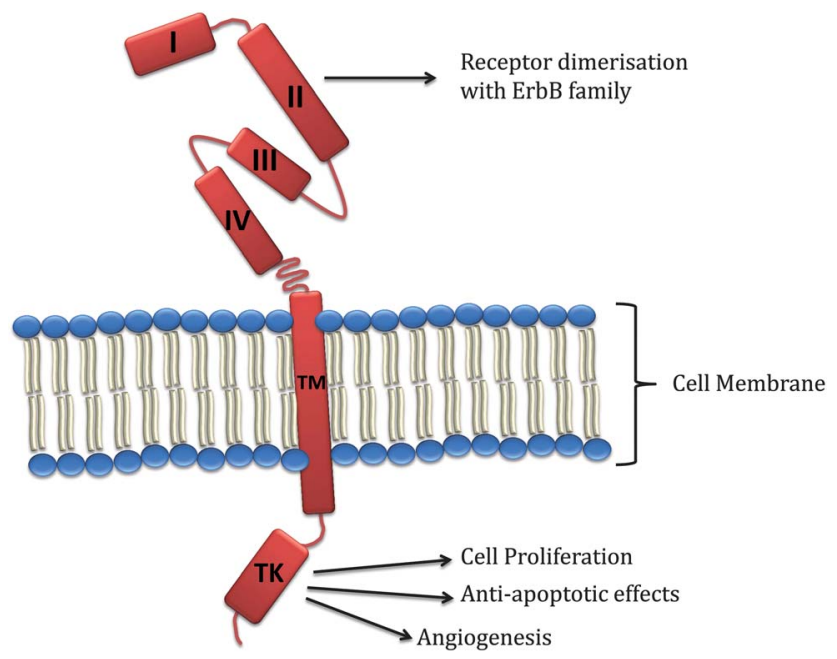

Fig. 1 Schematic representation of the classic ErbB2 protein. The full length protein consists of 1255 amino acids comprising an extracellular domain $(I-I V)$, transmembrane spanning region (TM) and an intracellular domain which holds tyrosine kinase (TK) activity. ErbB2 receptor dimerisation occurs through binding in the domain II. Receptor dimerisation results in initiation of downstream signalling events, facilitating processes such as cell proliferation, anti-apoptotic effects and angiogenesis. Figure adapted from Baselga \& Swain. ${ }^{3}$

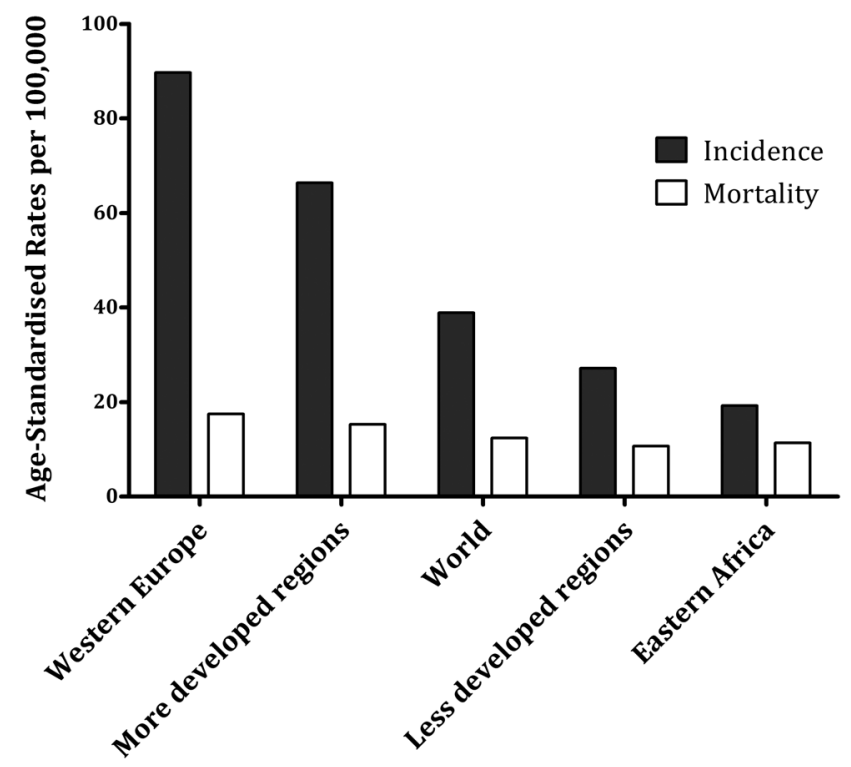

Fig. 2 Incidence (black bars) and mortality (white bars) rates (agestandardised per 100,000 population) for breast cancer. Graph constructed from data retrieved from Globocan 2008 (globocan.iarc.fr).

Clinical studies have shown that patients with ErbB2-overexpressing primary tumours have a significantly greater potential to propagate nodal involvement, and extensive lymphovascular invasion, resulting in poor prognosis compared to individuals with Luminal A or basal expression of ErbB2. ${ }^{13}$ The activity of ErbB2 (i.e. the degree of receptor dimerisation with other growth factor receptors) in tumour tissue contributes to the aggressive behaviour of ErbB2 cancer subtypes. ${ }^{14}$ Thus, accurate assessment
Table 1 Breast cancer molecular subtypes. Breast cancer subtypes can be classified based on the expression patterns of estrogen receptor, progesterone receptor and ErbB2 receptor on the cancer cell

\begin{tabular}{lccc}
\hline $\begin{array}{l}\text { Breast Cancer } \\
\text { Molecular Subtype }\end{array}$ & $\begin{array}{l}\text { Estrogen } \\
\text { receptor (ER) }\end{array}$ & $\begin{array}{l}\text { Progesterone } \\
\text { receptor (PR) }\end{array}$ & ErbB2 receptor \\
\hline Basal-like & - & - & - \\
Luminal A & + & + & - \\
Luminal B & + & + & + \\
ErbB2 & - & - & + \\
\hline
\end{tabular}

of ErbB2 in tumour cells holds significant diagnostic importance and may have therapeutic consequences.

\subsection{Soluble ErbB2: clinical importance in cancer diagnosis}

The soluble form of ErbB2 (sErbB2) (i.e., the proteolytically processed extracellular domain of the full length ErbB2 protein, and found circulating in blood) and has been shown to be released from breast cancer cells, ${ }^{15}$ and is recognised as a promising biomarker in profiling the progression of cancer, in particular, metastatic breast cancer. ${ }^{16}$ Several studies have shown correlation between the presence of ErbB2-overexpressing tumours and elevated levels of sErbB2 in patient blood fractions (Reviewed $i^{17}$ ). Measurement of sErbB2 may provide a more informative diagnostic tool, both in terms of overall ErbB2 load and monitoring tumour response to therapy. As mentioned before, ErbB2 is not a confined hallmark of a cancerous cell phenotype, and basal expression of ErbB2 is sometimes a feature of normal tissues. ${ }^{1}$ For this reason, it is unlikely that sErbB2 can be used as a sole and specific diagnostic marker of the presence of cancer in patients. However, an in-depth review of 22 studies has concluded that in the majority (85\%) of individuals surveyed, sErbB2 levels correlated with disease recurrence, metastasis or shortened survival. ${ }^{18}$ Taking this factor into consideration, the value of sErbB2 as a biomarker lies in assessing the metastatic state of ErbB2 cancers and seems to allow tracking of the response to anticancer treatments.

\subsection{Nanotechnological answers to current diagnostic limitations}

So far, current in vitro and in vivo clinical diagnostic practises still have a number of inherent limitations which are hampering development towards improved cancer treatment strategies.

At an in vitro diagnostic level, there is a routine reliance on a subjective, non-quantitative tumour grading system, namely immunohistochemistry (IHC), where parameters such as fixation may limit specificity of antigen detection, ${ }^{19}$ resulting in both false-positive and false-negative results. These may have a direct impact on the diagnostic observation and patient treatment. Furthermore, biopsy studies suggest that there is discordant ErbB2 expression between primary and metastatic sites within the same patient, ${ }^{6}$ and highlights the shortfall in 
accurate cancer diagnosis through reliance on assessment of the primary lesion alone.

In terms of blood fraction analysis, sErbB2 correlates well with disease behaviour and shows potential to measure susceptibility to cancer recurrence and response to treatment. ${ }^{18}$ However, assessment of sErbB2 levels alone may not be sufficient to accurately predict cancer status. Due to the heterogeneous nature of cancer progression, it is recognised that the future of effective cancer profiling lies in the simultaneous grading of multiple tumour markers. ${ }^{20}$ Additionally, the importance of assessing circulating tumour cells (CTCs) as a prognostic indicator of progression free survival and response to targeted therapy has been highlighted by recent evidence. ${ }^{21} \mathrm{~A}$ number of commercially available kits are available for assessing ErbB2 in CTCs, however, the level of inter-kit agreement merits further investigation. ${ }^{22}$

In addition to ErbB2 quantification, there is also a necessity for new techniques which measure the activity (e.g. degree of receptor dimerisation) of ErbB2 and other markers such as EGFR in tumour cells. This information can be gained by using techniques such as Förster resonance energy transfer (FRET) ${ }^{23}$ and may inform the clinician on the efficiency of targeted treatments by assessing the receptor activity. ${ }^{24}$

In vivo imaging techniques have been used for many years to visualise tumour tissue, however due to the non-specific distribution of contrast agent such as in X-ray computed tomography (XRCT), and short renal clearance times, the patient is often exposed to high contrast agent dose during the imaging procedure. Passive in vivo contrast agents (e.g. Indocyanine Green) naturally accumulate in vasculature and tumour tissue due to the enhanced permeability and retention (EPR) effect. $^{25}$ The EPR effect has been exploited in order to visualise tumours in vivo. However, EPR alone cannot provide the information regarding the molecular profile of the tumour tissue. Therefore, there is a demand for cancer-targeted in vivo imaging strategies which could reduce the overall burden on the patient whilst increasing cancer detectability and informing the clinician on the molecular phenotype of the tumour.

Although current established molecular profiling techniques have gone a long way to advancing the standard of medical treatment, there is a need to move towards more quantitative, objective cancer diagnostic systems in tissue biopsy and blood fractions analysis. In short, there is a need to improve the reliability and accuracy of disease diagnosis and to guide the selection of effective treatment for patients.

Over the past decade, nanotechnology-based diagnostic approaches have emerged as promising candidates for the improvement of clinical diagnostic techniques. The development of a number of families of nanoparticles (NPs), development of chemical linkers and antibody engineering have the potential to greatly enhance ErbB2 assessment to the point of single molecule detection. In addition, the development of nanowire (NW) structures for multiplexed "lab-on-a-wire" bioanalytical devices ${ }^{\mathbf{2 6 , 2 7}}$ has shown advantages in high throughput assays when compared to conventional and NP-based probe systems ${ }^{28}$ leading to the possibility of improved analyte detection sensitivity in biological assays.
The use of nanomaterials (NMs) (i.e. NPs and NWs) as biomarker sensors could overcome such shortfalls and limitations. In particular, NM-assays have two major advantages over conventional assays: ${ }^{29}$ (1) they enable higher imaging sensitivity and (2) they can merge multiple modalities on one probe (for example, NMs that can efficiently target cancer cells to combine biomarker detection with in vivo cancer imaging). ${ }^{\mathbf{3 0 , 3 1}}$

To date, a number of nanotechnological approaches have been translated to and approved for medical applications, and most of these are liposome-based and protein-polymer-based drug treatments. ${ }^{32,33}$ In spite of the success in translating nanotechnology-based treatments to the marketplace (recent examples include Marquibo ${ }^{\circledR}$ \& Bepanthen $\left.{ }^{\circledR}\right)$, there has been comparatively little translation of nano-research to everyday clinical diagnostic practise and this stimulates the quest for further nanotechnological breakthroughs. Given the clinical importance of ErbB2 we focus on the NM-based technologies which aim to improve ErbB2 detection and quantification for diagnostic purposes.

\section{Clinical methodologies for the detection and quantification of ErbB2}

Clinically, the molecular presence of ErbB2 in tumour tissue is identified by in situ hybridisation (ISH), which characterises ErbB2 gene copy number, and IHC, which measures ErbB2 protein content. Enzyme-linked Immuno-Sorbent Assay (ELISA) is one of the most common methods to quantify sErbB2 levels in patient blood fractions. ${ }^{34}$

\subsection{Genetic detection and quantification of ErbB2}

All DNA assessment techniques measure the predisposition potential toward a given proteomic phenotype and thus can act as an early detection system for cancer. Polyploidy is a common feature of cancer cells, ${ }^{35,36}$ and so measurement of the gene copy number can indicate the presence of pathologic cells. In clinical practise, genetic assessment of ErbB2 is generally used in conjunction with IHC results in order to confirm ErbB2 status in biopsy tissue.

In ISH, the nucleic acid probe is hybridised to its complimentary nucleic acid strand in the tissue section. Hybridisation allows the visualisation and enumeration of specific gene loci (Fig. 3) via a direct or indirect fluorescent (i.e. fluorescent in situ hybridisation; FISH) or chromogenic (i.e. chromogenic in situ hybridisation; CISH) tag. mRNA ISH (see Section 2.1.3) allows examination of the ErbB2 mRNA transcripts within the tissue section. Genomic hybridisation arrays and real-time polymerase chain reaction- (RT-PCR) based assays can measure a vast amount of genetic loci or gene transcripts at one time.

2.1.1. Fluorescent in situ hybridisation (FISH). Commercially available FISH assays for ErbB2 gene assessment (summarised in Table 2) employ direct labelling of the DNA with a complimentary DNA probe (which is directly conjugated to a fluorophore, such as Spectrum Orange ${ }^{\mathrm{TM}}$ in the PathVysion ${ }^{\mathrm{TM}}$ kit and TexasRed ${ }^{\circledR}$ in the Dako IQFISH ${ }^{\mathrm{TM}}$ kit) (Fig. 3). FISH assays are usually restricted to formalin-fixed paraffin-embedded tissue 


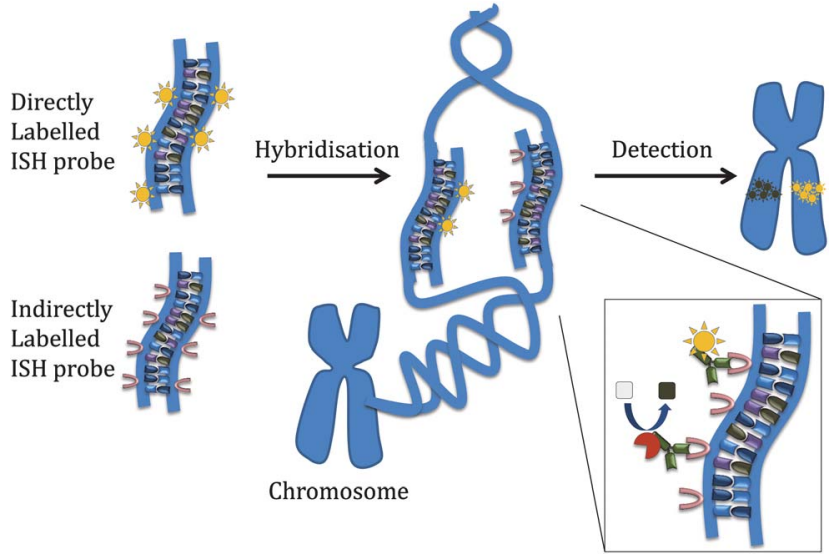

Fig. 3 Principle of in situ hybridisation. This figure represents the principles of ISH using either a directly- or indirectly- labelled method. In directly-labelled ISH, the DNA probe is directly conjugated to a fluorophore (yellow), as occurs in FISH. In indirectly-labelled ISH, the DNA probe is conjugated to a hapten (pink). During the denaturation step of the ISH protocol, the DNA probe hybridises to the gene of interest. Directly-labelled probes can then be visualised. Haptenconjugated probes are detected either with a chromogen-linked antibody (red) (CISH), or with a fluorescently-labelled antibody. sections, and probe hybridisation is carried out for 8-10 hours. Even though they are considered one of the gold standard techniques for the clinical profiling of tumours, successful use of FISH kits for ErbB2 quantification relies heavily on expert execution of complex laboratory protocols. On this topic Cayre et $a .^{37}$ have published an extensive comparative report on the different experimental outcomes obtained from a variety of commercially available ErbB2 FISH kits tested on the same samples. They concluded that the tested are very well in accordance with one another, however, this agreement was reliant on the relative adjustment of signal threshold levels. The technique appears therefore to be susceptible to user error. Finally, the resolution (ability to distinguish between two points on a chromosome length) of in situ hybridisation assays can also be affected by the cell cycle phase. ${ }^{38}$

2.1.2. Chromogenic in situ hybridisation (CISH). CISH allows the genetic assessment of tissue biopsies at lower magnifications compared to FISH. Thus, CISH can be used to measure gene ploidy within the greater context of the surrounding tissue. Although the resolution of CISH may not reach that of FISH, it is less costly and does not require specialised equipment, and so may be more suited to certain clinical situations.

Table 2 Diagnostic assays for ErbB2 gene and mRNA. The table details those commercially available assays used for clinical profiling of ErbB2 at a gene and mRNA level. The table was compiled based on on-site assay use and from a web search for ErbB2 diagnostic assays

\begin{tabular}{|c|c|c|c|c|c|}
\hline $\begin{array}{l}\text { ErbB2 form } \\
\text { detected }\end{array}$ & $\begin{array}{l}\text { Detection } \\
\operatorname{method}^{a}\end{array}$ & $\begin{array}{l}\text { Manufacturer } \\
\text { (country) }\end{array}$ & $\begin{array}{l}\text { Assay commercial } \\
\text { name }\end{array}$ & $\begin{array}{l}\text { Declared } \\
\text { sensitivity }\end{array}$ & $\begin{array}{l}\text { Clinical } \\
\text { sample }^{b}\end{array}$ \\
\hline \multirow{8}{*}{$\begin{array}{l}2.1 \text { Gene/mRNA } \\
\text { encoding for } \\
\text { ErbB2 }\end{array}$} & FISH & $\begin{array}{l}\text { Abbott Molecular, } \\
\text { Inc. (USA) }\end{array}$ & $\begin{array}{l}\text { PathVysion }^{\mathrm{TM}} \text { HER2 } \\
\text { DNA Probe Kit }\end{array}$ & $\begin{array}{l}\text { Ratio to reference gene } \\
\text { included in kit }\end{array}$ & FFPE \\
\hline & & $\begin{array}{l}\text { Dako Denmark } \\
\text { A/S (Denmark) }\end{array}$ & $\begin{array}{l}\text { HER2 IQFISH } \\
\text { pharmDx }^{\mathrm{TM}}\end{array}$ & & \\
\hline & CISH & $\begin{array}{l}\text { Ventana Medical } \\
\text { Systems, Inc. (USA) }\end{array}$ & INFORM ${ }^{\text {TM }}$ HER2 & Not stated & \\
\hline & & $\begin{array}{l}\text { Invitrogen Corporation } \\
\text { Ltd (USA) }\end{array}$ & $\begin{array}{l}\text { SPOT-Light@ HER2 } \\
\text { CISH Kit }\end{array}$ & Single gene copy & \\
\hline & & $\begin{array}{l}\text { Dako Denmark A/S } \\
\text { (Denmark) }\end{array}$ & HER2 CISH pharmDx ${ }^{\mathrm{TM}}$ & $\begin{array}{l}\text { Ratio to reference gene } \\
\text { included in kit }\end{array}$ & \\
\hline & RNA ISH & Affimetrix, Inc. (USA) & QuantiGene® ViewRNA & $\begin{array}{l}\text { Single RNA molecule } \\
\text { detection }\end{array}$ & \\
\hline & Microarray & $\begin{array}{l}\text { Genomic Health, Inc. } \\
\text { (USA) }\end{array}$ & Oncotype $\mathrm{DX}^{\mathrm{TM}}$ & $\begin{array}{l}\text { Ratio to } 5 \text { reference } \\
\text { genes } \\
\text { included in kit }\end{array}$ & \\
\hline & & Agendia (Netherlands) & MammaPrint $®$ & $\begin{array}{l}50 \% \text { tumour cell } \\
\text { content }\end{array}$ & $\begin{array}{l}\text { Fresh } \\
\text { tissue }\end{array}$ \\
\hline $\begin{array}{l}\text { mRNA from } \\
\text { circulating } \\
\text { tumour cells }\end{array}$ & $\begin{array}{l}\text { Immunomagnetic } \\
\text { separation and RT- } \\
\text { PCR }\end{array}$ & $\begin{array}{l}\text { Adnagen, Gmbh. } \\
\text { (Germany) }\end{array}$ & $\begin{array}{l}\text { AdnaTest BreastCancerSelect/ } \\
\text { BreastCancerSelect }\end{array}$ & $\begin{array}{l}30 \text { ng } \mu l^{-1} \text { amplified } \\
\text { cDNA }\end{array}$ & $\mathrm{S}$ \\
\hline
\end{tabular}

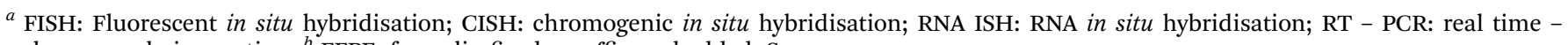
polymerase chain reaction. ${ }^{b}$ FFPE: formalin-fixed paraffin-embedded; S: serum. 
$\mathrm{CISH}$ relies on an indirect labelling method, whereby the DNA probe is conjugated to a hapten (e.g. INFORM or Spot-light kits, Table 2) against which an antibody is raised. Such antibodies are tagged with a chromogenic marker rather than a fluorophore as occurs in FISH. Interestingly, products supplied by Dako Denmark A/S use identical DNA probes in their FISH and CISH kits, with the latter simply adding antibodies against the FISH fluorophores (TexasRed ${ }^{\circledR}$ and Fluorescein). The chromogen is then converted to a visible product, usually by an enzymatic reaction (e.g. by addition of horseradish peroxidase (HRP) or alkaline phosphatase (AP)). CISH brings with it a few advantages over FISH assays. Firstly, indirect labelling with antihapten antibodies permits optical detection of ErbB2 genes at lower magnifications. Secondly, CISH stained samples can be archived without incurring sample or staining degradation. ${ }^{37}$ This advantage might be counteracted by incorporating stable nanotechnology-based fluorophores into FISH techniques.

2.1.3. mRNA in situ hybridisation (mRNA ISH). mRNA ISH quantifies the ErbB2 gene expression levels. This technique has some unique advantages over FISH and CISH assays. Firstly, mRNA ISH detects ErbB2 gene transcripts and thus is more representative of the ErbB2 transcriptome levels in tumour cells. A recent study has shown, however, that there is a close correlation between mRNA ISH and FISH when determining ErbB2 levels in primary breast tumours. ${ }^{39}$ Secondly, the reduced processing time (4 h) of samples by mRNA ISH makes this technique advantageous when compared to FISH and CISH approaches. Affimetrix's QuantiGene ViewRNA kit (Table 2) can detect up to four different RNA transcripts at a time. In this instance, branched DNA amplification technology ${ }^{\mathbf{4 0}}$ attached to the mRNA probe is used to amplify the captured target RNA (rather than relying on an in vitro reverse transcriptase amplification of mRNA), ${ }^{41}$ and visualisation of the amplified RNA is tailored for brightfield, fluorescent or luminescent detection. As an alternative to mRNA ISH, Adnagen (Germany) (Table 2) have developed a RT-PCR-based diagnostic which measures ErbB2 mRNA content as one of a panel of mRNA markers in CTCs. This is achieved through immunomagnetic concentration of CTCs from a blood sample followed by mRNA analysis. The technique assesses ErbB2 positivity through measurement of the final concentration of amplified cDNA.

2.1.4. Genomic hybridisation arrays. Hybridisation arrays consist of immobilised DNA probes on a solid matrix microarray, which can be used to measure gene copy number variations (the signal intensity correlates with hybridisation intensity) and to compare gene expression profiles among normal and tumourigenic DNA profiles. ${ }^{42}$ In contrast with the FISH approach, DNA (or cDNA generated from mRNA) for hybridisation arrays can be isolated from both fresh biopsy tissue and formaldehyde-fixed paraffin-embedded tissue.

Several microarrays are commercially available for assessing ErbB2 gene status. The FDA-approved MammaPrint (Agendia, Amsterdam) microarray assesses 70 genes (one of which is ErbB2 gene) associated with the development of distant metastases 5 years after surgery. ${ }^{43}$ The Oncotype DX (Genomic Health, Inc., CA) microarray also measures ErbB2 levels as one of sixteen tumour markers in comparison to five reference genes. ${ }^{44}$ One of the main advantages of microarrays is that they allow the simultaneous analysis of a number of genes which may better reflect the heterogenic nature of tumour development.

2.1.5. Appraisal of ErbB2 gene detection techniques. Table 2 illustrates clinical diagnostic assays for the detection and quantification of tissue ErbB2 at a genetic and post-transcriptional level. From a technical standpoint, in ISH the efficiency of probe hybridisation into native DNA is skewed towards detection in cells in interphase of the cell cycle ${ }^{38}$ and often considerable specialised equipment is required for some of the genetic assessment platforms. Microarray-based assays allow simultaneous quantification of numerous genes, however, the technique may also be more sensitive to contaminating DNA. ErbB2 mRNA quantification techniques (such as that developed by Adnagen) which rely on RTPCR in order to generate a detectable signal are ultimately limited by the quality and preparation of the sample mRNA.

One of the major limitations of the genetic detection/quantification methods for ErbB2 lies in the design of the DNA probe used. There is some preliminary evidence reporting the inaccuracy of ErbB2 FISH kits as determined by comparative gene hybridisation array analysis. ${ }^{45}$ Despite the fact that the ErbB2 gene comprises a $40 \mathrm{~kb}$ genomic region, most of the commercial ErbB2 probes currently commercialised for FISH/CISH assays consist of 190-218 kb length DNA probes (Vysis PathVysion: $190 \mathrm{~kb}$, Ventana INFORM: $200 \mathrm{~kb}$ and Dako IQFISH: 218 $\mathrm{kb}$, see Table 2) which may increase the chance of non-specific binding events. ${ }^{46}$ As one solution, Invitrogen has recently developed a proprietary 'subtractive hybridisation' technology (included in the SPOT-Light CISH kit), which removes repetitive sequences from its probes and generates higher specificity for the targeted ErbB2 gene. The incorporation of brighter fluorescent probes (based, for example, on quantum dot technology, as discussed in Section 3) might further allow improved gene resolution and gene quantification assays.

\subsection{Detection and quantification of ErbB2 protein}

The following sections address two of the conventional diagnostic approaches to quantify ErbB2 protein in tumour tissues and patient fluids. IHC represents the most commonly used clinical diagnostic method for semi-quantitative assessment of protein levels within the morphological context of tumour tissue biopsies (Table 3). IHC is a well-established and validated technique too, and no specialised equipment is needed. ELISAs are the main method for measuring soluble ErbB2 in blood fractions (Table 4). Since numerous studies correlate elevated blood sErbB2 levels with the presence of ErbB2-positive breast cancer tumours, ${ }^{34}$ sErbB2 ELISA is seen as a possible early detection system for ErbB2-positive cancers.

2.2.1. Immuno-histochemical detection of ErbB2 protein. IHC relies on using one specific antibody against the ErbB2 protein (Fig. 4A). Amplification of the signal is achieved by using enzyme linked- (e.g., HRP, AP or AP-anti-AP) secondary antibodies guided against the detection antibody. The enzymelinked antibody converts a substrate to a visible colour. Although good sensitivity can be achieved using this detection method, IHC uses only one ErbB2-specific antibody and nonspecific binding phenomena can occur. 
Table 3 Tissue diagnostic assays for the detection and quantification of human ErbB2 protein. The table details those commercially available assays used for clinical profiling of ErbB2 at a protein level. The table was compiled based on on-site assay use and from aweb search for ErbB2 diagnostic assays

\begin{tabular}{|c|c|c|c|c|c|}
\hline $\begin{array}{l}\text { Tissue ErbB2 form } \\
\text { detected }\end{array}$ & $\begin{array}{l}\text { Detection } \\
\text { method }^{a}\end{array}$ & $\begin{array}{l}\text { Manufacturer } \\
\text { (country) }\end{array}$ & $\begin{array}{l}\text { Assay commercial } \\
\text { name }\end{array}$ & $\begin{array}{l}\text { Declared } \\
\text { sensitivity }\end{array}$ & $\begin{array}{l}\text { Clinical sample } \\
\text { tested }^{b}\end{array}$ \\
\hline \multirow[t]{4}{*}{ ErbB2 protein } & IHC & Biogenex (USA) & $\begin{array}{l}\text { InSite }^{\mathrm{TM}} \text { HER2/neu } \\
\text { CB11 }\end{array}$ & $\begin{array}{l}>10 \% \text { Tissue } \\
\text { staining }\end{array}$ & FFPE \\
\hline & & $\begin{array}{l}\text { Dako Denmark } \\
\text { (Denmark) }\end{array}$ & Hercep Test ${ }^{\mathrm{TM}}$ & & \\
\hline & & $\begin{array}{l}\text { Ventana Medical } \\
\text { Systems, Inc. (USA) }\end{array}$ & $\begin{array}{l}\text { Pathway® anti } \\
\text { HER2/neu (4B5) }\end{array}$ & & \\
\hline & Proximity-based & $\begin{array}{l}\text { Monogram } \\
\text { Biosciences (USA) }\end{array}$ & $\begin{array}{l}\text { HERmark® Breast } \\
\text { Cancer Assay }\end{array}$ & Not stated & \\
\hline
\end{tabular}

Table 4 ELISAs for the detection and quantification of human ErbB2 in biological liquid fractions. The table details those commercially available ELISAs used for clinical profiling of soluble ErbB2 at a protein level. The table was compiled based on on-site assay use and from a web search for ErbB2 diagnostic assays

\begin{tabular}{|c|c|c|c|c|}
\hline $\begin{array}{l}\text { Soluble ErbB2 detection } \\
\text { method }^{a}\end{array}$ & $\begin{array}{l}\text { Manufacturer } \\
\text { (country) }\end{array}$ & $\begin{array}{l}\text { Assay commercial } \\
\text { name }\end{array}$ & $\begin{array}{l}\text { Declared } \\
\text { sensitivity }\end{array}$ & $\begin{array}{l}\text { Clinical sample } \\
\text { tested }^{b}\end{array}$ \\
\hline \multirow[t]{4}{*}{ ELISA } & WILEX, Inc. (USA) & Her2/neu ELISA & $1.5 \mathrm{ng} \mathrm{ml}^{-1}$ & $\mathrm{~S}$ \\
\hline & Abcam, plc (UK) & ErbB2 Human ELISA kit & $8 \mathrm{pg} \mathrm{ml}^{-1}$ & $\mathrm{U}, \mathrm{S}, \mathrm{P}$ \\
\hline & Ray Biotech, Inc. (USA) & $\begin{array}{l}\text { RayBio® Human ErbB2 } \\
\text { ELISA kit }\end{array}$ & $8 \mathrm{pg} \mathrm{ml}^{-1}$ & $\mathrm{U}, \mathrm{S}, \mathrm{P}$ \\
\hline & eBioscience, Inc. (USA) & $\begin{array}{l}\text { Human sHER-2 Platinum } \\
\text { ELISA }\end{array}$ & $0.06 \mathrm{ng} \mathrm{ml}^{-1}$ & $\mathrm{~S}, \mathrm{P}$ \\
\hline
\end{tabular}

Various IHC kits for ErbB2 measurement are available, such as that produced by Dako (Denmark) using Trastuzumab as the detection antibody. Whilst Trastuzumab targets the extracellular domain of ErbB2, Biogenex and Ventana Medical Systems have developed their own ErbB2 IHC kits with antibodies (mouse monoclonal antibody CB11 and rabbit monoclonal antibody 4B5, respectively) guided against the intracellular portion of the ErbB2 protein. Trastuzumab has a simpler access route to ErbB2 (effective CB11 and 4B5 staining relies on successful penetration of permiablised cells) and so is less likely to suffer from high background, non-specific staining. However, since there are sometimes a number of active, carboxy-terminal ErbB2 variants (which lack the extracellular domain) present in cells, ${ }^{47}$ there is a chance that IHC assessment via Trastuzumab may underestimate the true amount of active ErbB2 in the cell. A threshold of $>10 \%$ tissue staining is regarded as the minimum threshold for defining ErbB2 positivity by ErbB2 protein IHC kits (Table 3). Therefore, although IHC for ErbB2 is well established and widely used, the limited resolution of this technique makes it unsuitable for weakly expressed targets or for single-molecule detection. IHC gives the clinician a "reasonable" assessment of ErbB2 tissue load, however there are a number of limitations related to this technique. IHC is semi-quantitative, subjective, not sensitive at low ErbB2 expression ranges ( 0 to $1+$ ) and reliant on activity of staining reagents (e.g., peroxidase activity). ${ }^{48}$

2.2.2. Enzyme-linked immuno-sorbent assays (ELISAs). As illustrated in Table 4, a number of sErbB2 ELISA kits are available for quantification of sErbB2. ELISAs use two specific, target-directed antibodies (capture and detection antibodies), followed by an enzyme-driven amplification step (e.g., via HRPor AP-linked secondary antibodies) (Fig. 4B) with quantification of antigen achieved through comparison to a standard range. This approach increases the probability of specific detection of sErbB2. Thus, ELISA is a quantitative rather than a semiquantitative assay. Clinically, the FDA-approved cut-off concentration above $15 \mathrm{ng} \mathrm{ml} \mathrm{m}^{-1}$ for sErbB2 is considered indicative of the presence of ErbB2-overexpressing cancers. ${ }^{34}$

ELISAs have a number of advantages over IHC. ELISAs are quantitative, easy to use, have relatively short assay time and have 


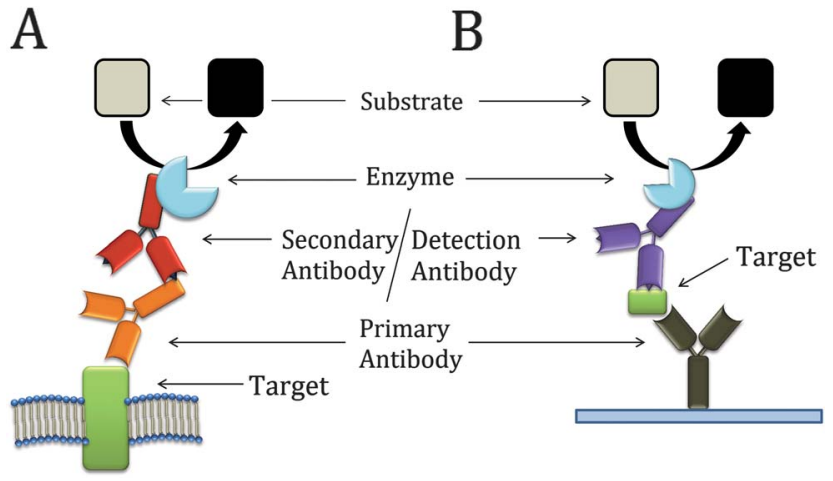

Fig. 4 Principle of (A) IHC and (B) sandwich ELISA. (A) In IHC, detection of the antigen (green) is accomplished by an antigen-specific primary antibody (orange), followed by detection and signal amplification via an enzyme (light blue) -linked secondary antibody (red) in the presence of a substrate. (B) In ELISA, both antibodies are directed against the antigen (green). The first antibody (grey) is immobilised on an assay well. Following capture of the antigen, the enzyme-linked detection antibody (purple), generates the chromogenic signal.

very sensitive detection limits. Furthermore, ELISA is able to assess the pooled sErbB2 circulating in blood, which could give us a better indication of the overall cancer status of the patient. However, there is some evidence of sErbB2 false positive in patients without cancer, with elevated levels of sErbB2 being reported in cases of liver cirrhosis. ${ }^{49}$ However, this does not negate the utility of assessing sErbB2 as a cancer detection strategy. The drawbacks associated with ELISAs include high cost of the assay, usually only mono-parametric detection (Table 4) and the absence of histological context of protein quantification. ELISA is also unsuitable for quantification of CTCs.

\section{Enhancing ErbB2 detection using nanotechnology-based tools}

Despite the advances in the development of genetic and protein assessment technologies, there is now a requirement to bring clinical diagnostics to new levels of molecular specificity and sensitivity. From a clinical standpoint, NMs provide the vehicle with which to improve routine clinical diagnostic techniques with respect to signal detection fidelity, single cell and analyte detection sensitivity and multiplexing of biomarker analysis. In the case of ErbB2 detection, there is a clinical need for gene probes with improved specificity (see limitations in Section 2.1.5) and protein probes with improved signal-to-noise ratio for the accurate determination of circulating biomarkers. ${ }^{50}$

\subsection{Nanomaterials for molecular imaging and detection purposes}

In recent years, exploitation of the unique properties of NMs (such as superior optical, magnetic and plasmonic properties, altered catalytic properties, high surface-area to volume ratio, and the possibility of surface modification) have facilitated higher sensitivity and specificity in biomarker detection. As a consequence, there are a wealth of NM-based technologies under development for biomarker detection utilising quantum

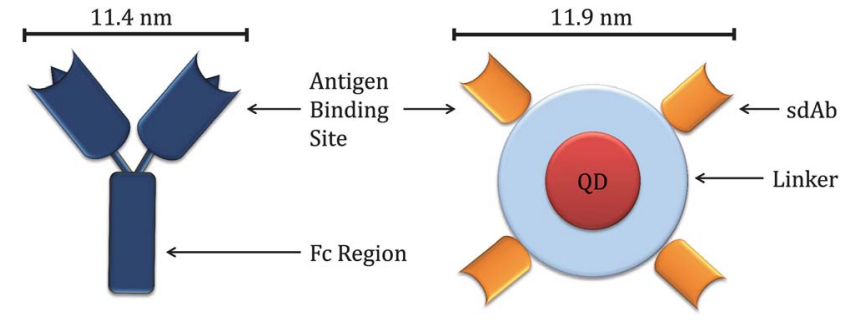

Fig. 5 Size comparison between (A) conventional immunoglobulin and (B) immune-functionalised quantum dot (QD). Abbreviations: $\mathrm{sdAb}$ : single-domain antibody fragment. Adapted from Sukhanova et al. 2011.

dots (QDs), superparamagnetic iron oxide NPs (SPIONs), noble metal NPs such as gold NPs (Au NPs) and silver NPs (Ag NPs), carbon nanotubes (CNTs) and silica nanowires (Si NWs). ${ }^{51,52}$

The use of chemical linkers such as polyethylene glycol (PEG), (3-aminopropyl) triethoxysilane (APTES) and dextran has enabled functionalisation of NPs with bioactive molecules such as antibodies, ligands, biocompatibility agents and drug candidates ${ }^{53-55}$ and has opened up the possibility of exploiting NPs for biological detection. This development has allowed NPs to be aimed against specific targets for visualising molecular interactions (such as immune function) and investigating therapeutic pathways. ${ }^{56}$ For example, surface modification of NPs with PEG has permitted the conjugation of engineered ultra-small single domain antibodies to superbright stable fluorescent NPs (QDs, discussed in Section 3.2.1.2) (Fig. 5). ${ }^{57}$ This synthesis allows twice as many antibody binding sites to be incorporated into the same space as a monoclonal antibody and is currently being developed for targeting ErbB2 in cell populations using flow cytometry. ${ }^{58}$ In the in vivo setting, functionalised superparamagnetic NPs have been successfully investigated for use as tumour-targeted nuclear magnetic resonance imaging (NMRI) contrast agents. ${ }^{59}$ Furthermore, it is hoped that the functionalisation of NPs with cancer-targeting moieties will reduce the administered dose used for in vivo tumour imaging. The following sections illustrate the NP-based technologies being developed for the advancement of in vitro and in vivo ErbB2 cancer diagnostics and imaging.

\subsection{Nanoparticle applications in in vitro ErbB2 assays}

Some NP applications for in vitro detection of ErbB2 are illustrated in Table 5. An overview of the technical details associated with each NP format is given, and an attempt is made to evaluate the potential for these technologies to transition effectively to clinical practise.

Although some attempts have been made to apply NPs to in vitro genetic assessment of ErbB2, ${ }^{\mathbf{6 0}, \mathbf{6 1}}$ mixed successes have been observed. The vast majority of NP technologies applied in ErbB2 profiling are based on detecting the protein form rather than the gene target, providing significant progress towards improving current diagnostics. Section 3.2 discusses the applications of nanotechnologies to ErbB2 in vitro diagnostics. 


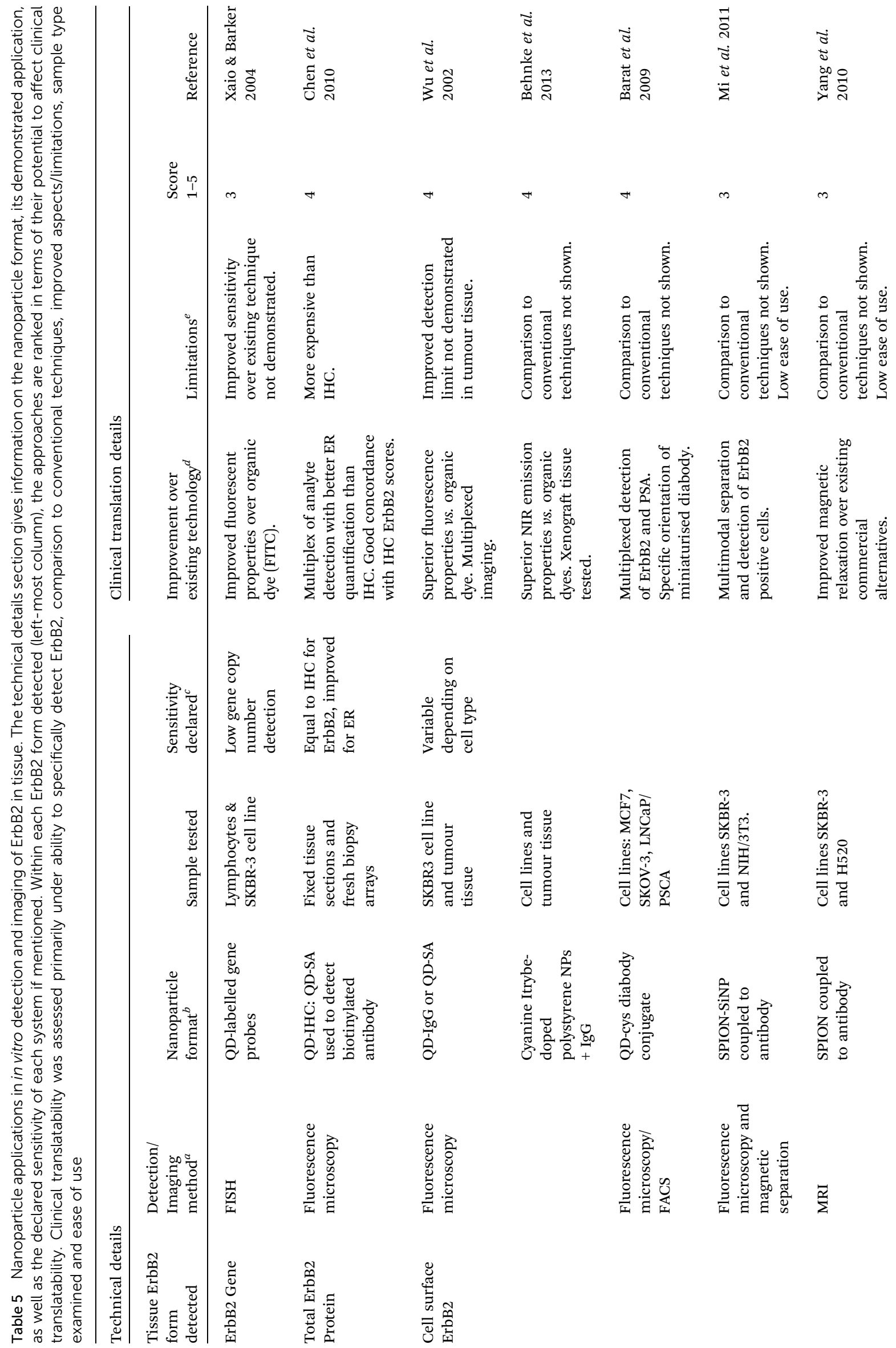




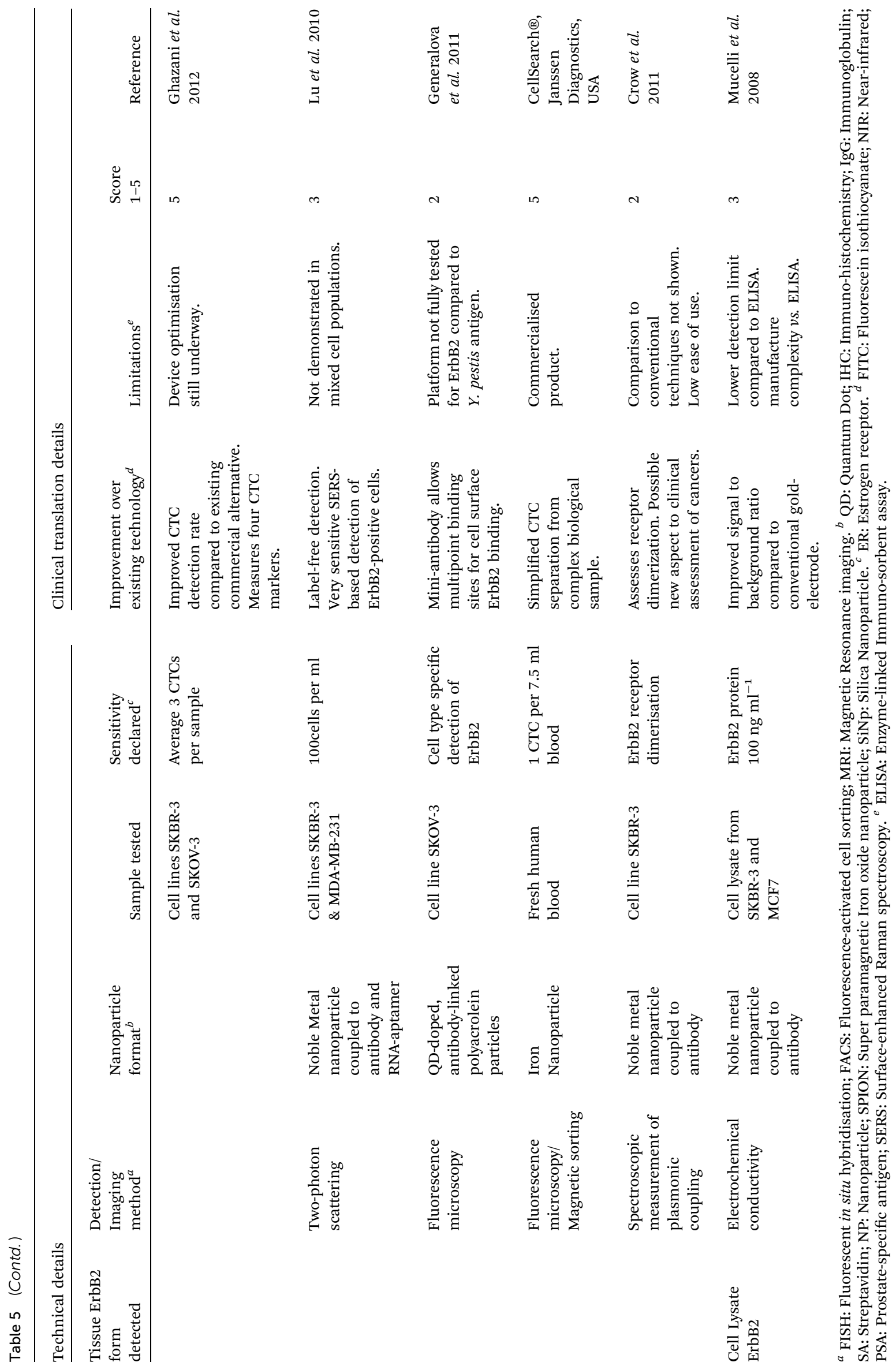


A

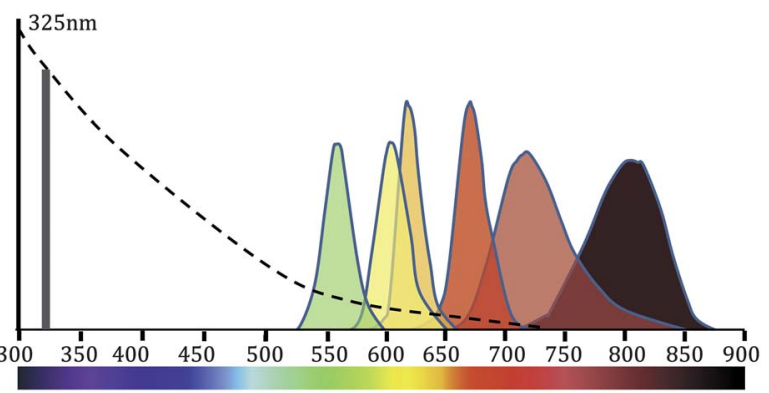

Wavelength (nm)

B

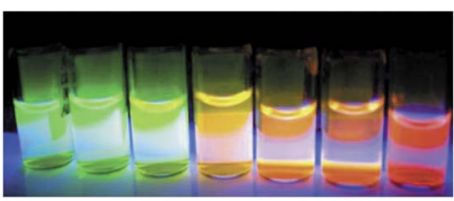

Fig. 6 (A) Absorption (dotted line) and emission (coloured curves) spectra of QDs. In general, QDs strongly absorb short wavelength radiation. Emission spectrum peaks represent the wavelength at which maximum fluorescent intensity can be measured from an excited QD. The emission wavelength is relative to QD size, assuming QD composition is the same. Commercially available QDs excited by a single UV light source (e.g. $325 \mathrm{~nm}$ ) fluoresce in the visible and nearinfrared spectrum (500-800 nm). (B) Image of QDs in solution under fluorescent excitation. Image courtesy of Dr. A. Rakovich (Imperial College London).

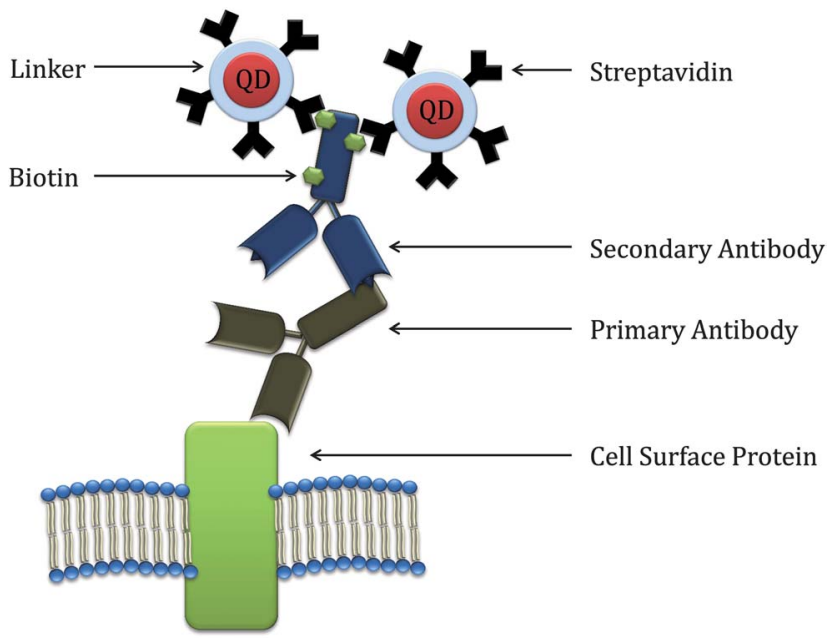

Fig. 7 Schematic of streptavidin-coupled QD for detection of proteins through binding to biotinylated secondary antibody (Adapted from Howarth et al. ${ }^{67}$ ).

\subsubsection{Nanoparticles in optical detection of ErbB2}

3.2.1.1. Fluorescent quantum dots. Quantum dots (QDs), described as luminescent semiconductor nanocrystals, hold intrinsic properties which could vastly improve the quality, fidelity and durability of optical imaging for biomarker detection. QDs exhibit superior fluorescent quantum yield compared to organic dyes, higher photostability (an advantage in archiving of biological samples), broad absorption spectra, narrower emission peaks, tuneable emission wavelengths and their small dimensions allows them to penetrate tissue barriers.
In terms of fluorescent properties, QDs far outperform the commonly used FISH kit organic fluorophores such as fluorescein $^{62}$ and Texas Red ${ }^{63}$ and have been applied in a FISH detection system. ${ }^{60}$

Another significant advantage of using QDs for diagnostic assays is that multiple QDs can be excited by a single noncoherent light source, such as an ultra-violet (UV) lamp (Fig. 6). This reduces the need for specialised equipment and associated costs. Additionally, QDs emission peaks can be tuned to desirable wavelengths by modifying their size ${ }^{63}$ allowing the development of simple-to-use multiplexed assays. ${ }^{64}$

3.2.1.2. Optical detection of ErbB2 protein in vitro using quantum dots. QDs have been used for the detection of ErbB2 in IHC-based assays and are being developed toward the detection of rare CTCs in patient blood fractions. ${ }^{65}$ QDs conjugated to streptavidin and incorporated into a conventional IHC protocol can act as a signal amplifier for biotinylated secondary antibodies $^{66,67}$ (Fig. 7). Wu et al. ${ }^{66}$ demonstrated multiplexed detection of ErbB2 and nuclear antigens using QD-IgG or QD-streptavidin, and showed the favourable photostability of QDs over organic dyes. In tumour tissue samples, ErbB2 protein has been detected in breast cancer core biopsy using QDs (ZnS/CdSe, $605 \mathrm{~nm}$ emission peak), with improved results over traditional IHC in terms of quantification of ErbB2. ${ }^{68,69}$ In this case, the improved visual contrast in QD-stained samples compared to traditional ErbB2 IHC allowed software-based statistical analysis of the tissue sections in terms of fluorescence intensity and distribution area. Using two different emission spectrum QDs (605 $\mathrm{nm}$ and $545 \mathrm{~nm}$ ) this approach was successfully used to simultaneously image ErbB2 and ER in breast cancer sections. ${ }^{64}$

QDs have been impregnated into submicron polyacroline particles, followed by antibody functionalisation, to create an ErbB2 probe for in vitro cell imaging. ${ }^{70}$ Although QDs have also been applied to the assessment of ErbB2 gene copy number, ${ }^{60}$ and improved fluorescent properties over an organic dye were demonstrated, a more recent publication ${ }^{61}$ has shown that in the case of FISH, the reproducibility of ErbB2 gene detection was more difficult with QD-based assays.

QD-based IHC performs well at detecting low level expression of ErbB2 in tissue. ${ }^{68}$ By utilising fluorescent-linked probes rather than enzymatically-linked probes, QDs help to move IHC from a semi-quantitative, subjective diagnostic technique towards a quantitative, objective one. This NP-based application has the potential to improve current clinical diagnostics through standardisation of tissue scoring systems.

3.2.1.3. Multiplexed fluorescence-activated cell sorting (FACS) using quantum dots. FACS allows the quantitative, multiplexed examination of molecular markers within a cell population by simultaneously processing multiple fluorophore signals, each fluorophore being linked to a specific marker. Due to their inherent photostability and tuneable fluorescent emission wavelength, the use of quantum dots rather than organic dyes is set to improve the performance of FACS as a diagnostic technique. FACS has been used to detect surface ErbB2 expression in cancer cell lines in suspension using fluorescent QDs directly conjugated to ErbB2-specific antibody fragments 
Table 6 Main physical properties of Gold and Silver Nanoparticles. The left column shows the property with the corresponding application listed in the right column

Gold and silver nanoparticle

features

Bioimaging application

Localised surface plasmonic resonance

Surface plasmon resonance imaging

Intense raman scattering profile

Surface enhanced Raman spectroscopy

Two photon luminescence

Two photon emission microscopy

X-ray radiopacity

X-Ray computer tomography

Electroconductive

Electrochemical detection

(cys-diabodies), ${ }^{71}$ and the selective detection of ErbB2-positive cells (MCF7, SKOV-3) vs. prostate specific antigen-expressing cell lines (LnCap, PSCA) using QDs has been demonstrated. Although this work was carried out using cell lines in solution, it may be possible to apply QDs to CTC detection in patient blood fractions.

To date QD-based techniques have shown more promise for improving the quality of ErbB2 protein assays rather than ErbB2 gene assays in vitro. The combination of their superb optical properties, functionalisation potential and nanometer size has allowed QDs to be adapted to different diagnostic platforms such as IHC and FACS. ${ }^{68,71,72}$ This adaptability has significant future implications in terms of increasing the reliability of comparison between different diagnostic techniques.

\subsubsection{Detection of ErbB2 using metal nanoparticles}

3.2.2.1. Noble metal nanoparticles. Gold (Au) and silver (Ag) NPs possess a number of properties (e.g. localised surface plasmon resonance, enhanced Raman scattering, electroconductivity photoelectric potential, biocompatibility, lack of photobleaching) which can be exploited in clinical diagnostic techniques for the detection of ErbB2. ${ }^{73,74}$ Table 6 below lists some of the main physical properties of Au and Ag NPs alongside their application in the detection and imaging of biomarkers.

3.2.2.1.1. Localized surface plasmon resonance (LSPR). Noble metal NPs (such as Au NPs and Ag NPs) exhibit localized surface plasmon resonance (LSPR), which can be defined as enhanced optical absorption and scattering at a specific peak resonant wavelength. This property is tuneable by altering composition, size and shape of the NPs, as well as the surrounding dielectric medium. ${ }^{75}$ Seekell et al. ${ }^{76}$ demonstrated the multiplexed detection of ErbB2 along with two other cancer biomarkers in various cancer cell populations using antibody-functionalised Au NPs and Ag NPs in flow cytometry. Additionally, LSPR has been used to study receptor dimerisation of ErbB2 by observing plasmonic coupling between adjacent NPs, ${ }^{77}$ adding an additional interrogative power to future assay development.

3.2.2.1.2. Surface-Enhanced Raman Spectroscopy (SERS). Raman spectroscopy is a non-destructive, non-invasive optical method which is based on the inelastic scattering of light. ${ }^{78}$
Exceptionally intense Raman scattering is an inherent property of metal NPs such as Au NPs and Ag NPs, and this property has led to their use in surface-enhanced Raman spectroscopy (SERS). Since Raman scattering from metal NPs is often several orders of magnitude greater than non-metalic molecules, it makes them ideal for detection in a complex system. For example, binding of an analyte to functionalised metal NPs will cause a shift in the Raman spectrum of that NP, indicating that analyte binding has occurred.

The detection of ErbB2-positive cancer cells in vitro using SERS has been achieved by coupling antibodies to the surface of $\mathrm{Au} \mathrm{NPs}^{73}$ In this study, Raman scattering was measured through the skin of nude mice following subcutaneous injection of Au NPs. In a follow-up study, the same group demonstrated SERS detection of cancer xenografts in mice, using functionalised Au NPs. ${ }^{74}$ Similarly, Ag NPs have been used to differentiate between ErbB2-positive and ErbB2-negative cell lines using SERS. Improvements in the design and functionalization of NM-based SERS detectors will ultimately facilitate the widespread use of SERS for diagnostic purposes.

These studies demonstrate the potential application of targeted noble metal NPs in ErbB2 assays. Since this technique is not ideal for in vivo cancer imaging at depths greater than a few millimetres, SERS is likely to become a replacement or companion to in vitro cancer diagnostic kits. ${ }^{79}$

3.2.2.1.3. Two photon scattering. Another result of the surface plasmon resonance displayed by metal NPs is the enhanced scattering of incident light (termed two photon scattering or hyper-Rayleigh scattering) at the second harmonic wavelength. Functionalised gold NPs have been used to discriminate between ErbB2-positive (SKBR-3) and -negative (MDA-MB-231) cell lines in a PBS suspension using this technique. ${ }^{80}$ In the presence of ErbB2-positive cells, the two-photon scattering intensity increased compared to the ErbB2-negative cell line. Lu et al. ${ }^{\mathbf{8 0}}$ also demonstrated that the scattering-based system was two orders of magnitude more sensitive (100 cells per $\mathrm{ml}$ ) than the colourimetric equivalent in detecting ErbB2positive cancer cells.

3.2.3. Nanoparticles in detection of soluble ErbB2 and circulating tumour cells. The electroconductivity of gold NMs has also been exploited to create an electrochemical detection system for sErbB2. Mucelli et al. ${ }^{81}$ demonstrated the detection of ErbB2 in SKBR-3 and MCF7 cell lysate preparations using Trastuzumab-functionalised gold nanoelectrodes which generate an electrocatalytic signal upon analyte binding. Although the detection system showed successful detection of ErbB2 in a complex biological solution, the detection limits attained by this setup were not improved over current ELISA detection limits. The detection of CTCs using nanomaterialbased technologies, as demonstrated in the CTC model by Lu et al., ${ }^{82}$ has been met with some success and a NP-based system has been commercialised (CellSearch ${ }^{\circledR}$, Janssen Diagnostics, Inc., Belgium) which uses functionalised magnetic nanoparticles to separate CTCs from whole blood. Ghazani et al. ${ }^{\mathbf{8 3}}$ have demonstrated the detection of CTCs based on a combined four-marker biomarker set (Epithelial Cell Adhesion Molecule, ErbB2, ErbB1 and Mucin-1). This multiplexed approach uses 


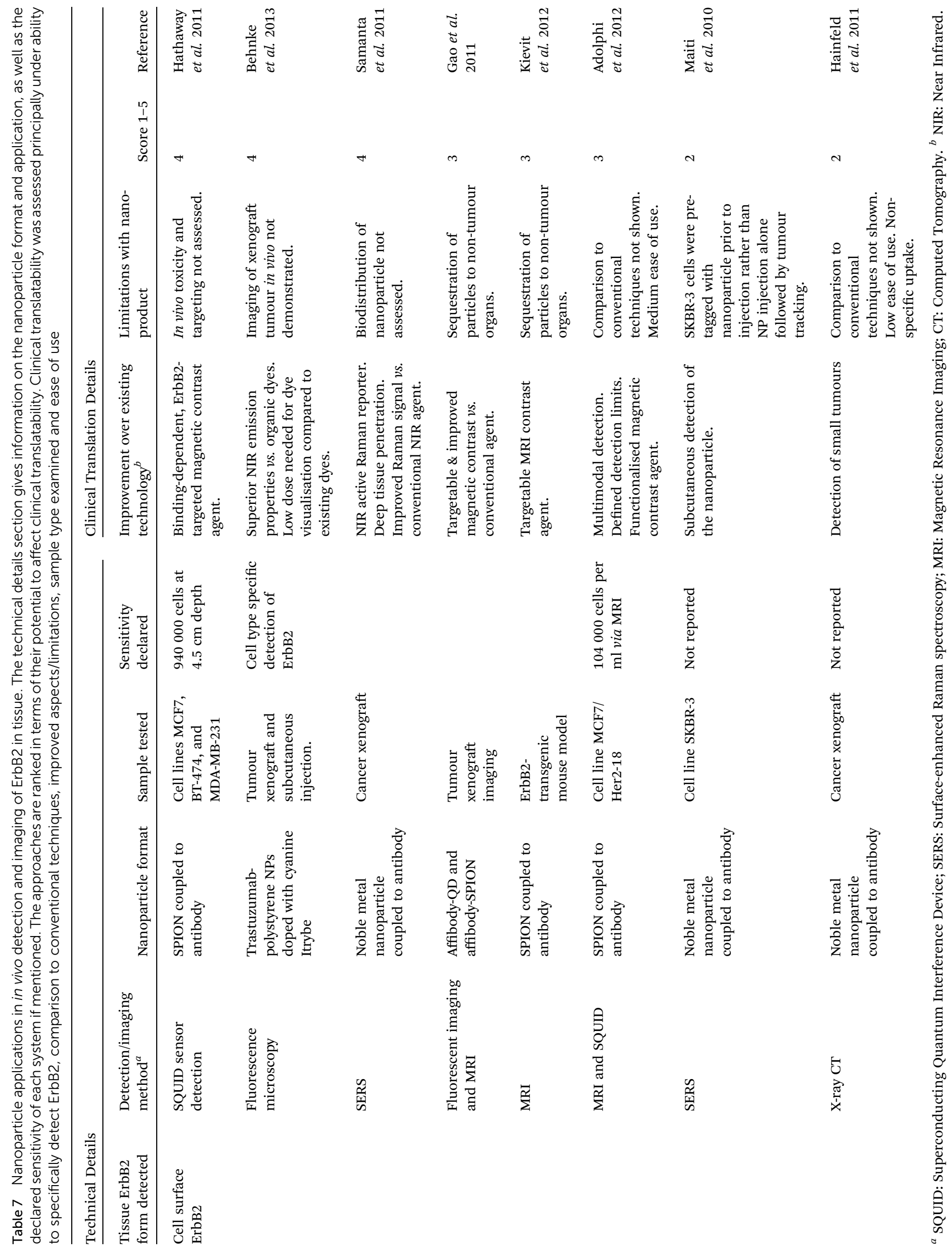


micro-NMRI to detect functionalised iron oxide nanoparticles in a complex blood sample, without the need for primary CTC isolation. This offers greater chance of capturing CTCs and illustrates how measuring multiple targets may increase the diagnostic predictive value of a clinical in vitro diagnostic.

\subsection{Nanoparticle applications for in vivo ErbB2 imaging}

In vivo imaging techniques allow the assessment of internal anatomical structures. Techniques such as X-ray computed tomography (XRCT) (Section 3.3.2) and Magnetic resonance imaging (MRI) (Section 3.3.3) have become invaluable as medical assessment and diagnostic tools. More recently, nearinfrared (NIR) spectrum contrast agents have been demonstrated as suitable superficial tissue contrast agents. ${ }^{84}$ Despite the advances made towards in vivo imaging, there are a number of aspects associated with these imaging modalities which need to be improved upon (e.g. administered contrast agent dose, short renal clearance times, non-specific distribution of contrast agents and reliance on the EPR effect alone for the visualisation of tumours). Due to their size, composition, and functionalisation potential, some NPs are suitably positioned to provide answers to the current in vivo imaging needs. NMs can be tuned to achieve desired renal clearance times and so provide a concrete opportunity for multimodal imaging of malignancies. ${ }^{85}$ NMs can naturally accumulate in tumours due to the EPR effect, and this quality may be enhanced through NM functionalisation in order to increase the sensitivity and specificity of ErbB2 tumour detection. The following section (summarised in Table 7) illustrates the application of nanotechnologies towards the enhancement of in vivo ErbB2 cancer detection.

When developing NPs such as SPIONs, polystyrene beads, noble metal NPs and QDs for in vivo applications (see Table 7), cytotoxicity and biocompatibility issues must be considered. Many of these particles have been incorporated into liposomes for a variety of different applications to best maximise the delivery of localised drug or contrast imaging enhancer where necessary. ${ }^{32}$ In this respect, only those particles that have already been assessed or evaluated in their associated risk for in vivo imaging are considered. Over the past 10 years, iron oxide nanoparticle formulations have been brought through preclinical and clinical evaluation and are available as FDA- or EMA-approved MRI contrast agents, such as Endorem ${ }^{\circledR}$ (Feridex IV) and Resovist ${ }^{\circledR}$ (Cliavist ${ }^{\circledR}$ ). Therefore, in the case of SPIONs, cytotoxicity and biocompatibility have been taken into account during the pre-clinical and clinical phase I trials. Currently, a number of EU FP7 projects (such as the MULTIFUN project) are engaged in the development of a new generation multifunctional SPION for theranostic application for in vivo applications. ${ }^{86}$ Polystyrene (PS) beads have been extensively used as a biocompatible multimodal system for enhanced imaging. PS beads have been proven to have several advantages from their controllable sizes to their tunable functional responses with the surrounding tissue. ${ }^{87}$

$\mathrm{Au}$ and $\mathrm{Ag}$ have been extensively used for their plasmonic imaging properties and antibacterial properties, ${ }^{88}$ respectively.
The biocompatibility of Ag NPs is illustrated by several products on the market including bandages, plasters, tiles, and paints which all work on the principle of nano-Ag antibacterial principle. The "nano-" formulations of gold may be advantageous for tackling very specific disease and healthcare applications, and gold NP formulations such as Aurimmune ${ }^{\circledR}$ are currently in phase II trials for solid tumour treatment. ${ }^{33}$ That aside, there are at least $5 \mathrm{Au}$ NP products on the market commercially available which have been approved for cancer imaging and theranostic purposes. ${ }^{89}$

In the past 10 years, QDs have been proven to be the future alternative to colorimetric dyes due to their intrinsic properties. Several studies have also provided evidence for in vivo applications. ${ }^{90,91}$ The speculations in this respect are twofold: (1) QDs if properly coated can be made biocompatible and non-cytotoxic and (2) the efficacy of real-time QD imaging in vivo in lifethreatening (or irreversible) disease can overcome the localised biocompatible limitation of the QD core (in the eventuality that this will be fully exposed to biological tissue/fluid).

Furthermore, in all nanomaterials here presented there is growing evidence from the physico-chemical applications that these can be designed (or assembled) into a multi-layer configuration to reduce, prevent or neutralise any possible adverse aspect derived from the interaction with the in vivo biological tissue or fluid. ${ }^{92}$ This is particularly true for iron oxide, Ag and Au NPs due to either the low toxicity or inert nature. ${ }^{93,94}$

3.3.1. Optical imaging of ErbB2 protein in vivo using nearinfrared-emitting nanoparticles. In vivo optical imaging techniques have limited depth penetration through human tissues. However, materials which emit light in the NIR spectrum ( 700-1600 nm wavelength radiation) have particular advantages for in vivo molecular imaging due to the fact that these wavelengths are minimally absorbed by body tissues. ${ }^{95}$ However, to date many organic NIR imaging probes have been limited in clinical use due to aqueous insolubility, aggregate formation and small Stokes shifts. ${ }^{96}$ The ability of QDs to emit efficiently in the NIR makes them promising candidates as NIR contrast agents and have focused attention on the development of NM-based probes for subcutaneous in vivo imaging. ${ }^{97}$ Issues surrounding the in vivo use of QDs such as long term in vivo distribution, clearance, and toxicity QDs needs to be characterised $^{\mathbf{9 8}}$ before they can be deemed suitable for optical imaging as an in vivo diagnostic tool.

For example, Gao et al. ${ }^{99}$ coupled an anti-ErbB2 affibody to the surface of QDs, followed by systemic probe injection and imaging of human SKOV-3 tumours in immune compromised mice. NIR fluorescence (NIRF) in vivo imaging showed that functionalised anti-ErbB2 QDs selectively bound to and accumulated in SKOV-3 tumours compared to non-functionalised PEG-coated QDs. Lately, Trastuzumab-functionalised polystyrene NPs containing NIR-emitting heptamethine dye have been developed to facilitate in vivo imaging of ErbB2-positive tumours. ${ }^{100}$ These particles have shown to successfully detect ErbB2 in cancer cell lines and fixed tumour tissues. In vivo, the same NPs could be visualised by NIRF imaging when injected subcutaneously into mice, leading to the possibility of use as future in vivo imaging probes. 
There are still a number of obstacles to overcome before QDs or other NPs become common-place in in vivo diagnostic and clinical practise. Although NIR QDs would be useful in vivo imaging of superficial cancers, their application is depth-limited to not more than $3-4 \mathrm{~cm}$. In addition, the cytotoxicity of QDs ${ }^{101}$ and ability to selectively target tumour tissue still need to be fully addressed. Due to their sequestration in non-cancerous organs, QDs will most likely not be systemically administered, but administered directly to the tissue of interest. Parameters such as NP size, composition, surface functionalisation and administered dose all contribute to whether NPs will be used in vivo. Despite possessing excellent fluorescent properties (such as tuneable NIR spectrum emission) there is still a way to go before QDs will be considered safe for in vivo imaging of cancers.

Although in vivo NIR-imaging is depth-restricted, a relatively new and exciting NP-based in vivo imaging technology has emerged from NPs which exhibit the phenomenon of second harmonic generation (SHG). SHG occurs when mono-chromatic electromagnetic radiation is passed through an optically nonlinear material and generates an output wave with double the frequency to that of the incident radiation. This phenomenon is a property of materials with a non-centrosymmetric crystal lattice structure, and can be found in nanomaterials such as CNTs, ZnO and GaN nanowires, and nanocrystals such as BiTiO $_{3}{ }^{102}$ Advantages of using SHG for bioimaging include tuneable output frequency radiation and minimal unspecific background interference. Additionally, SHG is not restricted by an absorption/excitation spectra window and is not prone to bleaching or blinking effects. ${ }^{103}$ These characteristics make particles which possess SHG ideal for deep tissue in vivo imaging through measurement of coherent interference from NP populations. Although ErbB2 imaging in vivo using SHG has not been demonstrated yet, it is an avenue of research which looks very promising for future clinical applications, especially in imaging biopsies.

3.3.2. X-ray Computed Tomography (XRCT) of ErbB2 tumours using metal nanoparticles. XRCT, also known as Computed Tomography (CT) or Computed Axial Tomography



Fig. 8 Principle of X-ray computed tomography. (A) Schematic of $\mathrm{XRCT}$ in a clinical setting; $\mathrm{X}$-rays (blue oscillating wave) pass through the patient's body and are detected on the opposite side (brown rectangles) to the $\mathrm{X}$-ray generator (red). The attenuated $\mathrm{X}$-rays collected by the detector are converted into a digital signal for image processing. (B) The molecular underpinnings behind XRCT; In the body, atoms such as hydrogen $(H)$ do not attenuate $X$-rays whilst iodine (I) contained within contrast agents measurably block X-rays. (C) The potential use of Au NPs in XRCT. Au NPs (yellow) readily block $X$-rays and can be tumour targeted by functionalising the Au NP surface with antibodies (Ab).
(CAT) images in vivo architecture based on obstruction of $\mathrm{X}$ radiation by tissue structures. ${ }^{\mathbf{1 0 4}}$ Contrast agents (such as iodine) are used to enhance radiopacity for imaging purposes (Fig. 8); however short renal clearance times of such contrast agents require high doses to be administered, thus raising toxicity issues. Loading tumour marker antibodies with CT contrast agents has attempted to reduce the administered dose needed but insufficient iodine loading on the antibody resulted in suboptimal CT conditions. ${ }^{\mathbf{1 0 5}}$

Several noble metal and non-noble metal NPs (namely bismuth (Bi) and ytterbium (Yb) NPs) with high radiopacity have been developed as CT contrast agents in an attempt to target and improve image contrast in in vivo CT imaging. ${ }^{106}$ The main advantages of using nanotechnology-based contrast agents include tuneable blood half-life, and a high X-ray attenuation coefficient as compared to iodine, making it useful as a potential contrast agent. ${ }^{\mathbf{1 0 7}}$

In a proof of principle study, Trastuzumab-functionalised $\mathrm{Au}$ NPs were used to detect ErbB2-positive cancer xenografts in mice using Micro-CT. ${ }^{\mathbf{1 0 5}}$ This study demonstrated accumulation of anti-ErbB2 Au NPs to the tumour site and detection of small tumours $(1.5 \mathrm{~mm})$. However, significant nonspecific accumulation of unconjugated $\mathrm{Au}$ NPs in ErbB2-positive and ErbB2negative tumours (possibly due to EPR effect) appears to limit their use as ErbB2-specific in vivo targeting tools.

3.3.3. Magnetic imaging of ErbB2 tumours using magnetic nanoparticles. For many years, MRI (which measures proton density and relaxation rate in a magnetic field) has been used for the non-invasive, three-dimensional imaging of in vivo tumours ${ }^{108}$ (Fig. 9). Conventional MRI relies on a pre-contrast and post-contrast image in order to locate and define the tumour from the high resolution background image ${ }^{109}$ and requires significant anatomical knowledge on behalf of the analyst in order to identify the tumour relative to surrounding tissue.

In order to enhance tumour image contrast, efforts have been made to couple contrast agents such as radioactive elements ${ }^{\mathbf{1 1 0}}$ to anti-ErbB2 ligands in an attempt to improve the

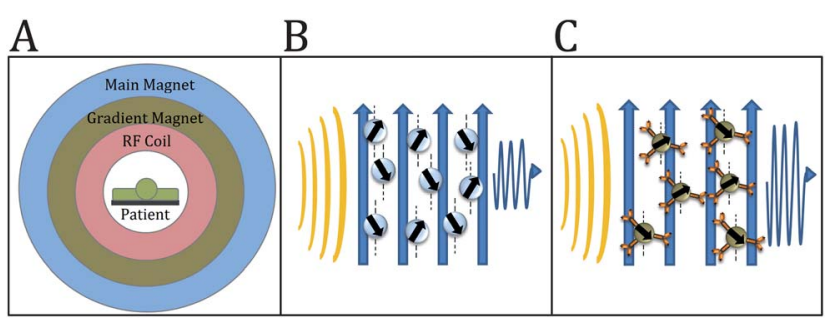

Fig. 9 Principle of magnetic resonance imaging. (A) Schematic of MRI in a clinical setting: the main magnet and gradient magnet are used to align the atomic nuclei within the patient's body. (B) The molecular underpinnings behind MRI: the radio frequency (RF) coil is used to alter atomic alignment and a magnetic moment is released from the atoms as they relax to their normal magnetic alignment. (C) The use of SPIONs in MRI. SPIONS generate a large magnetic moment when returning to their normal magnetic alignment. The attached antibodies (orange) will allow targeting of SPIONs to tumour tissue. Key: yellow bands: radio frequency; vertical blue arrows: magnetic field; Oscillating blue arrow: released energy from relaxing proton/superparamagnetic NP. 
detection of ErbB2-positive cancer. Still the low biocompatibility of these contrast agents has spurred researchers to investigate novel nanotechnology-based magnetic labels. Superparamagnetic iron oxide nanoparticles (SPIONs) are one of the main categories of NMs used as magnetic contrast agents. Their surface can be functionalised with bioactive marker ligands such as antibodies and can be coated with biocompatible materials such as silica. ${ }^{111}$ These non-radioactive, biocompatible SPIONs have been used to detect ErbB2 in vitro, ${ }^{112}$ and can be used to separate ErbB2-positive SKBR-3 cells from ErbB2negative NIH/3T3 cells in an in vitro model for cancer cell sorting. ${ }^{113}$ However, their real value will probably be found in in vivo applications where deep penetrating tissue contrast agents are necessary. The potential of SPIONs as valuable in vivo magnetic contrast agents has been demonstrated in murine tumour xenograft explants, ${ }^{59}$ where anti-ErbB2-conjugated SPIONs injected into ErbB2-expressing xenografts yielded higher magnetic response via superconducting quantum interference device (SQUID), compared to unconjugated SPIONs. MRI of anti-ErbB2-conjugated SPIONs in a nonimmune-compromised ErbB2-transgenic mouse model ${ }^{114}$ demonstrated significant shortening in $T_{2}$ magnetic relaxation time in the tumour region compared to no injection, and suggests that these SPIONs can provide contrast enhancement in tumour tissue. Although the decrease in $T_{2}$ was larger in antiErbB2 SPIONs compared to IgG-conjugated SPIONs, the difference was not statistically significant at the low sample number used $(n=3)$.

More recently, magnetic relaxometry of SPIONs measured by SQUID offer the chance to significantly improve in vivo imaging of tumour tissue over MRI imaging. SQUID sensors are tuned to only capture the magnetic field relaxation of target-bound NPs, thus eliminating background contrast interference. SQUID measurements improve therefore the magnetic signal-to-noise ratio of the tumour but loose the context of tumour positioning within tissue. ${ }^{115}$ This deficit can be overcome by integrating SQUID measurements with SQUID-detected ultra-low-field-MRI. Hathaway et al. ${ }^{59}$ used SQUID sensors to detect ErbB2-positive tumour explants using anti-ErbB2 conjugated SPIONs. Notably, these nanotechnology-based probes allowed the detection of low numbers of labelled tumour cells within breast phantom tissue at a depth of nearly 5 centimetres. Commercially available SPIONs (Endorem ${ }^{\circledR}$ ) are being trialled for the SQUID-based magnetic detection of cancerous sentinel lymph nodes in breast cancer patients. ${ }^{116}$

Direct comparison of SPIONs detection of ErbB2-positive cancers by MRI and magnetic relaxometry showed that both techniques are able to detect and image MCF7/Her2-18 tumour xenografts in mice. High sensitivity in tumour detection was possible by SQUID detection of targeted SPIONs, ${ }^{117}$ however the lack of comparison to ErbB2-negative tumour xenografts means that the specificity of the functionalised SPIONs was not fully tested.

With the ability to functionalise their surfaces, magnetic NPs are set to become the magnetic contrast agents of the near future, providing targetable, non-radioactive imaging tools for specific cancer subtypes. SQUID sensor developments, as well as other advantages of relaxometry (such as linear magnetic moment relative to NP number) may provide additional sensitivity for the generation of high quality imaging tools to diagnose tumours. However, as with the use of other NPs in vivo, a significant consideration is the sequestration of SPIONs by noncancerous organs such as the liver and kidneys. These issues may be addressed through NP engineering approaches and surface functionalisation.

\section{Conclusions}

Clinically, ErbB2 overexpression is considered to be an important marker for a number of solitary and metastatic cancers and sErbB2 is recognised as a promising blood biomarker in profiling ErbB2-positive cancer progression. Although current clinical diagnostic approaches give the clinician a reasonable assessment of ErbB2 load within a patient, this review highlights the inherent limitations of these systems and underscores the need for new technologies which aim to bring clinical diagnostics to new levels of molecular specificity and sensitivity.

The option to functionalise NPs with ligands has the potential to improve clinical diagnosis of ErbB2 with respect to sensitivity, objectivity and multiplexing of biomarker analysis for clinical diagnostic applications. Although currently, NMbased technologies may sometimes suffer from limitations such as batch-to-batch reproducibility, ${ }^{118}$ it is expected that with constantly improving understanding of NP synthesis and functionalisation, the advantages of NP-based diagnostics will be fully realisable.

In vitro, NMs such as QDs provide a real opportunity to improve the quality of ErbB2 diagnostics, particularly in protein quantification assays. QDs have been used to improve the sensitivity and objectivity of a routine ErbB2 IHC diagnostic, for a more robust disease staging. QD use in FACS has the potential to simplify multiplexed cancer assays, thus increasing the confidence which clinicians can place in the diagnostic readout. Additionally, noble metal NP application to SERS-based and electroconductive ErbB2 detection systems is likely to enhance future in vitro cancer diagnostic kits. The availability of functionalised SPIONs as a commercially viable diagnostic product (CellSearch $®$ ) for simplified CTC detection in complex patient sample, illustrates the benefits that NMs can bring to improving the simplicity and specificity of in vitro ErbB2 cancer diagnostic assays.

In vivo, NPs are suitably positioned to meet medical demands for targeted imaging of cancers. The ability of QDs to emit efficiently in the NIR makes them promising NIR contrast agents and has focused attention on the development of QD for subcutaneous in vivo imaging. Other NMs which possess SHG may be ideal for deep tissue in vivo cancer imaging. In terms of enhancing existing in vivo cancer imaging techniques, several functionalised noble metal NMs have been developed in an attempt to target and improve image contrast in XRCT imaging. This NP application has achieved detection of small tumour populations, though issues of nonspecific accumulation of unconjugated $\mathrm{Au}$ NPs in ErbB2-positive and ErbB2-negative tumours appears to limit their widespread application for ErbB2-specific tumour detection for the time being. 
SPIONs are a category of NMs which are already commercially available for use as in vivo magnetic contrast agents and it is hoped that this NM type will be further refined to provide cancer-targetable imaging tools for specific cancer subtypes such as ErbB2, while reducing the dose administered to the patient. SPION development, along with magnetic sensor improvements (such as SQUID), may provide additional sensitivity for the generation of high quality detection tools to diagnose ErbB2-specific tumours in depth.

To conclude, limitations in current in vitro and in vivo ErbB2 diagnostic approaches are hindering the advancement of cancer treatments against this often-aggressive molecular subtype. The development of more reliable methods to assess ErbB2 load and activity in tissue and blood fractions will inevitably help to improve the quality of treatment which cancer patients receive. To this end, there is a demand for in vitro and in vivo ErbB2 assays with increased sensitivity, specificity and multiplexed ability. A range of NMs have been developed to meet some of these medical needs, and the current and potential benefits of NM-based ErbB2 assays have been illustrated. From the assessment of the current scientific and technological developments surrounding ErbB2 detection, it is expected that in the next five to ten years several of the preclinical NM-based techniques and methodologies described are set to be translated into practise for the benefit of the patients, clinicians and healthcare providers.

\section{Conflict of interest}

We declare to have no conflict of interest related to the submission of this review.

\section{Abbreviations}

$\begin{array}{ll}\text { AP } & \text { Alkaline phosphatase } \\ \text { APTES } & \text { (3-Aminopropyl) triethoxysilane } \\ \text { CISH } & \text { Chromogenic in situ hybridisation } \\ \text { CNT } & \text { Carbon nanotube } \\ \text { CTC } & \text { Circulating tumour cell } \\ \text { DNA } & \text { Deoxyribonucleic acid } \\ \text { EGFR } & \text { Epidermal growth factor receptor } \\ \text { ELISA } & \text { Enzyme-linked immuno-sorbent assay } \\ \text { EPR } & \text { Enhanced permeability and retention } \\ \text { ErbB2 } & \text { Epidermal growth factor receptor 2 } \\ \text { ER } & \text { Estogen receptor } \\ \text { FACS } & \text { Fluorescence activated cell sorting } \\ \text { FDA } & \text { Food and Drug Administration } \\ \text { FISH } & \text { Fluorescent in situ hybridisation } \\ \text { HRP } & \text { Horseradish peroxidase } \\ \text { IgG } & \text { Immunoglobulin G } \\ \text { IHC } & \text { Immunohistochemistry } \\ \text { LSPR } & \text { Localised surface plasmon resonance } \\ \text { mRNA } & \text { Messenger ribonucleic acid } \\ \text { NIR } & \text { Near-infrared } \\ \text { NM } & \text { Nanomaterial } \\ \text { NMRI } & \text { Nuclear magnetic resonance } \\ \text { NP } & \text { Nanoparticle } \\ & \end{array}$

$\begin{array}{ll}\text { NW } & \text { Nanowire } \\ \text { PEG } & \text { Polyethylene glycol } \\ \text { PR } & \text { Progesterone receptor } \\ \text { QD } & \text { Quantum dot } \\ \text { RT-PCR } & \text { Real-time polymerase chain reaction } \\ \text { SERS } & \text { Surface enhanced Raman spectroscopy } \\ \text { SHG } & \text { Single harmonic generation } \\ \text { SPION } & \text { Superparamagnetic iron-oxide nanoparticle } \\ \text { SQUID } & \text { Superconducting quantum interference device } \\ \text { TK } & \text { Tyrosine kinase } \\ \text { TM } & \text { Transmembrane } \\ \text { UV } & \text { Ultra violet } \\ \text { XRCT } & \text { X-ray computed tomography. }\end{array}$

\section{Acknowledgements}

Sincere thanks to Dr Jennifer Conroy for useful and helpful discussions on Raman Spectroscopy. This work has been partially funded by the European Commission Framework 7 Programme under the large scale NAMDIATREAM project (\#246469).

\section{References}

1 A. Negro, B. Brar, Y. Gu, K. Peterson, W. Vale and K.-F. Lee, ErbB2 is required for $\mathrm{G}$ protein-coupled receptor signaling in the heart, Proc. Natl. Acad. Sci. U. S. A., 2006, 103(43), 15889-15893.

2 D. Yu and M.-C. Hung, Overexpression of ErbB2 in cancer and ErbB2-targeting strategies, Oncogene, 2000, 19, 61156121.

3 J. Baselga and S. Swain, Novel anticancer targets: revisiting ERBB2 and discovering ERBB3, Nat. Rev. Cancer, 2009, 9(7), 463-475.

4 C. Bargmann, M. Hung and R. Weinberg, The neu oncogene encodes an epidermal growth factor receptor-related protein, Nature, 1986, 319(6050), 226-230.

5 T. Yamamoto, S. Ikawa, T. Akiyama, K. Semba, N. Nomura, N. Miyajima, et al. Similarity of protein encoded by the human c-erb-B-2 gene to epidermal growth factor receptor, Nature, 1986, 319(6050), 230-234.

6 E. Lanitis, D. Dangaj, I. Hagemann, D.-G. Song, A. Best, R. Sandaltzopoulos, et al. Primary human ovarian epithelial cancer cells broadly express HER2 at immunologically-detectable levels, PLoS One, 2012, 7(11), e49829.

7 A. Dulak, S. Schumacher, J. van Lieshout, Y. Imamura, C. Fox, B. Shim, et al. Gastrointestinal adenocarcinomas of the esophagus, stomach, and colon exhibit distinct patterns of genome instability and oncogenesis, Cancer Res., 2012, 72(17), 4383-4393.

8 K. Ugocsai, L. Mándoky, L. Tiszlavicz and J. Molnár, Investigation of HER2 overexpression in non-small cell lung cancer, Anticancer Res., 2005, 25(4), 3061-3066.

9 S.-C. Wang, H.-C. Lien, W. Xia, I. F. Chen, H.-W. Lo, Z. Wang, et al. Binding at and transactivation of the COX- 
2 promoter by nuclear tyrosine kinase receptor ErbB-2, Cancer Cell, 2004, 6(3), 251-261.

10 C. G. Murphy and P. G. Morris, Recent advances in novel targeted therapies for HER2-positive breast cancer, Anticancer Drugs, 2012, 23(8), 765-776.

11 Cancer Genome Atlas N, Comprehensive molecular portraits of human breast tumours, Nature, 2012, 490(7418), 61-70.

12 K. Maryam, M. Negar, J. Azadeh, S. Ahmad and H. Niloufar, Breast Cancer Molecular Subtypes and Associations with Clinicopathological Characteristics in Iranian Women, 2002-2011, Asian Pacific Journal of Cancer Prevention, 2012, 13, 1881-1886.

13 L. Wiechmann, M. Sampson, M. Stempel, L. Jacks, S. Patil, T. King, et al. Presenting features of breast cancer differ by molecular subtype, Ann. Surg. Oncol., 2009, 16(10), 2705-2710.

14 D. N. Amin, N. Sergina, D. Ahuja, M. McMahon, J. A. Blair, D. Wang, et al. Resiliency and vulnerability in the HER2HER3 tumorigenic driver, Sci. Transl. Med., 2010, 2(16), 16 ra7.

15 P. C. C. Liu, X. Liu, Y. Li, M. Covington, R. Wynn, R. Huber, et al. Identification of ADAM10 as a major source of HER2 ectodomain sheddase activity in HER2 overexpressing breast cancer cells, Cancer Biol. Ther., 2006, 5(6), 657-664.

16 W. Carney, R. Neumann, A. Lipton, K. Leitzel, S. Ali and C. Price, Potential clinical utility of serum HER-2/neu oncoprotein concentrations in patients with breast cancer, Clin. Chem., 2003, 49(10), 1579-1598.

17 W. P. Carney, D. Bernhardt and B. Jasani, Circulating HER2 Extracellular Domain: A Specific and Quantitative Biomarker of Prognostic Value in all Breast Cancer Patients?, Biomarkers Cancer, 2013, 5, 31-39. Epub 2013/ 11/02.

18 J. Ross, J. Fletcher, G. Linette, J. Stec, E. Clark, M. Ayers, et al. The Her-2/neu gene and protein in breast cancer 2003: biomarker and target of therapy, Oncologist, 2003, 8(4), 307-325.

19 F. Penault-Llorca, J. Adelaïde, G. Houvenaeghel, J. Hassoun, D. Birnbaum and J. Jacquemier, Optimization of immunohistochemical detection of ERBB2 in human breast cancer: impact of fixation, J. Pathol., 1994, 173(1), 65-75.

20 F. R. Hirsch, M. Varella-Garcia and F. Cappuzzo, Predictive value of EGFR and HER2 overexpression in advanced non-small-cell lung cancer, Oncogene, 2009, 28(Suppl. 1), S32-S37.

21 Y. Liu, Q. Liu, T. Wang, L. Bian, S. Zhang, H. Hu, et al. Circulating tumor cells in HER2-positive metastatic breast cancer patients: a valuable prognostic and predictive biomarker, BMC Cancer, 2013, 13, 202.

22 T. Fehm, V. Müller, B. Aktas, W. Janni, A. Schneeweiss, E. Stickeler, et al. HER2 status of circulating tumor cells in patients with metastatic breast cancer: a prospective, multicenter trial, Breast Cancer Res. Treat., 2010, 124(2), 403-412.

23 B. R. Waterhouse, M. Gijsen, P. R. Barber, I. D. C. Tullis, B. Vojnovic and A. Kong, Assessment of EGFR/HER2 dimerization by FRET-FLIM utilizing Alexa-conjugated secondary antibodies in relation to targeted therapies in cancers, Oncotarget, 2011, 2(9), 728-736.

24 N. Gaborit, C. Larbouret, J. Vallaghe, F. Peyrusson, C. Bascoul-Mollevi, E. Crapez, et al. Time-resolved fluorescence resonance energy transfer (TR-FRET) to analyze the disruption of EGFR/HER2 dimers: a new method to evaluate the efficiency of targeted therapy using monoclonal antibodies, J. Biol. Chem., 2011, 286(13), 11337-11345.

25 J. Napp, J. E. Mathejczyk and F. Alves, Optical imaging in vivo with a focus on paediatric disease: technical progress, current preclinical and clinical applications and future perspectives, Pediatr. Radiol., 2011, 41(2), 161-175. Epub 2011/01/12.

26 F. Patolsky, G. Zheng and C. Lieber, Nanowire sensors for medicine and the life sciences, Nanomedicine, 2006, 1(1), 51-65.

27 G.-J. Zhang and Y. Ning, Silicon nanowire biosensor and its applications in disease diagnostics: a review, Anal. Chim. Acta, 2012, 749, 1-15.

28 A. Prina-Mello, A. Whelan, A. Atzberger, J. McCarthy, F. Byrne, G.-L. Davies, et al. Comparative flow cytometric analysis of immunofunctionalized nanowire and nanoparticle signatures, Small, 2010, 6(2), 247-255.

29 S. Bhaskar, F. Tian, T. Stoeger, W. Kreyling, J. de la Fuente, V. Grazú, et al. Multifunctional nanocarriers for diagnostics, drug delivery and targeted treatment across blood-brain barrier: perspectives on tracking and neuroimaging, Part. Fibre Toxicol., 2010, 7(1), 3.

30 C. S. S. R. Kumar, Nanomaterials for Medical Diagnosis and Therapy, ed. C. S. S. R. Kumar, WILEY-VCH, Weinheim, 2007.

31 C. S. S. R. Kumar, Nanomaterials for Cancer Diagnosis, ed. C. S. S. R. Kumar, WILEY-VCH, Weinheim, 2006.

32 C. Schütz, L. Juillerat-Jeanneret, H. Mueller, I. Lynch and M. Riediker, Therapeutic nanoparticles in clinics and under clinical evaluation, Nanomedicine, 2013, 8(3), 449467.

33 M. L. Etheridge, S. A. Campbell, A. G. Erdman, C. L. Haynes, S. M. Wolf and J. McCullough, The big picture on nanomedicine: the state of investigational and approved nanomedicine products, Nanomedicine, 2013, 9(1), 1-14.

34 W. Carney, R. Neumann, A. Lipton and K. Leitzel, Monitoring the circulating levels of the HER2/neu oncoprotein in breastcancer, Breast Cancer, 2004, 5(2), 105-116.

35 Z. Storchova and D. Pellman, From polyploidy to aneuploidy, genome instability and cancer, Nat. Rev. Mol. Cell Biol., 2004, 5(1), 45-54.

36 S. Zhang, I. Mercado-Uribe, Z. Xing, B. Sun, J. Kuang and J. Liu, Generation of cancer stem-like cells through the formation of polyploid giant cancer cells, Oncogene, 2013. Epub 2013/03/25.

37 A. Cayre, F. Mishellany, N. Lagarde and F. Penault-Llorca, Comparison of different commercial kits for HER2 testing in breast cancer: looking for the accurate cutoff for amplification, Breast Cancer Res., 2007, 9(5), R64. 
38 C. O'Connor, Fluorescence in situ hybridization (FISH), Nature, 2008, 1(1), 171.

39 J. Alba, J. Gutierrez, V. M. Coupe, B. Fernández, Á. VázquezBoquete, J. Alba, et al. HER2 status determination using RNA-ISH-a rapid and simple technique showing high correlation with FISH and IHC in 141 cases of breast cancer, Histol. Histopathol., 2012, 27(8), 1021-1027.

40 G. Tsongalis, Branched DNA technology in molecular diagnostics, Am. J. Clin. Pathol., 2006, 126(3), 448-453.

41 T. Horn, C. Chang and M. Urdea, Chemical synthesis and characterization of branched oligodeoxyribonucleotides (bDNA) for use as signal amplifiers in nucleic acid quantification assays, Nucleic Acids Res., 1997, 25(23), 4842-4849.

42 S. Cavallaro, S. Paratore, F. de Snoo, E. Salomone, L. Villari, C. Buscarino, et al. Genomic analysis: Toward a new approach in breast cancer management, Crit. Rev. Oncol. Hematol., 2012, 81(3), 207-223.

43 E. A. Slodkowska and J. S. Ross, MammaPrint ${ }^{\mathrm{TM}}$ 70-gene signature: another milestone in personalized medical care for breast cancer patients, Expert Rev. Mol. Diagn., 2009, 9(5), 417-422.

44 M. Cronin, C. Sangli, M.-L. Liu, M. Pho, D. Dutta, A. Nguyen, et al. Analytical Validation of the Oncotype DX Genomic Diagnostic Test for Recurrence Prognosis and Therapeutic Response Prediction in Node-Negative, Estrogen Receptor-Positive Breast Cancer, Clin. Chem., 2007, 53(6), 1084-1091.

45 H. L. McArthur, E. Brogi, S. Patil, M. Wigler, L. Norton and J. Hicks, et al. High resolution microarray copy number analysis (array CGH) suggests that determination of HER2 amplification by FISH (FISH + ) is inaccurate in human breast cancer specimens that are HER2 2+ by immunohistochemistry (IHC2+), in Joint ECCO 15-34th ESMO Multidisciplinary Congress, ed J. Smyth, 20-24 September BERLIN: European Journal of Cancer Supplements, 2009, p. 88.

46 M. Allison, The HER2 testing conundrum, Nat. Biotechnol., 2010, 28(2), 117-119.

47 J. Arribas, J. Baselga, K. Pedersen and J. L. Parra-Palau, p95HER2 and breast cancer, Cancer Res., 2011, 71(5), 1515-1519. Epub 2011/02/24.

48 L. True and X. Gao, Quantum dots for molecular pathology: their time has arrived, J. Mol. Diagn., 2007, 9(1), 7-11.

49 R. Molina, J. Jo, X. Filella, J. Bruix, A. Castells, M. Hague, et al. Serum levels of C-erbB-2 (HER-2/neu) in patients with malignant and non-malignant diseases, Tumour Biol., 1997, 18(3), 188-196.

50 L. Lam, N. McAndrew, M. Yee, T. Fu, J. C. Tchou and H. Zhang, Challenges in the clinical utility of the serum test for HER2 ECD, Biochim. Biophys. Acta, 2012, 1826(1), 199-208. Epub 2012/04/24.

51 X. Chi, D. Huang, Z. Zhao, Z. Zhou, Z. Yin and J. Gao, Nanoprobes for in vitro diagnostics of cancer and infectious diseases, Biomaterials, 2012, 33(1), 189-206.

52 S. Ray, P. Reddy, S. Choudhary, D. Raghu and S. Srivastava, Emerging nanoproteomics approaches for disease biomarker detection: a current perspective, J. Proteomics, 2011, 74(12), 2660-2681.

$53 \mathrm{~K}$. Costas and K. Olga, Nanoscale carriers for targeted delivery of drugs and therapeutic biomolecules, Can. J. Chem. Eng., 2013, 91, 2660-2681.

54 A. Martin, B. Li and E. Gillies, Surface functionalization of nanomaterials with dendritic groups: toward enhanced binding to biological targets, J. Am. Chem. Soc., 2009, 131(2), 734-741.

55 D. K. Bhowmick, S. Linden, A. Devaux, L. De Cola and H. Zacharias, Functionalization of Amorphous $\mathrm{SiO} 2$ and 6H-SiC(0001) Surfaces with Benzo[ghi]perylene-1,2Dicarboxylic Anhydride via an APTES Linker, Small, 2012, 8(4), 592-601.

56 M. Walling, J. Novak and J. Shepard, Quantum dots for live cell and in vivo imaging, Int. J. Mol. Sci., 2009, 10(2), 441-491.

57 A. Sukhanova, K. Even-Desrumeaux, A. Kisserli, T. Tabary, B. Reveil, J.-M. Millot, et al. Oriented conjugates of singledomain antibodies and quantum dots: toward a new generation of ultrasmall diagnostic nanoprobes, Nanomedicine: nanotechnology, biology and medicine, 2012, 8(4), 516-525.

58 A. Sukhanova, K. Even-Desrumeaux, J.-M. Millot, P. Chames, D. Baty and M. Artemyev, et al., Oriented conjugates of monoclonal and single-domain antibodies with quantum dots for flow cytometry and immunohistochemistry diagnostic applications, Proc SPIE 8232, Colloidal Nanocrystals for Biomedical Applications VII; 2012/02/09.

59 H. Hathaway, K. Butler, N. Adolphi, D. Lovato, R. Belfon, D. Fegan, et al. Detection of breast cancer cells using targeted magnetic nanoparticles and ultra-sensitive magnetic field sensors, Breast Cancer Res., 2011, 13(5), R108.

60 Y. Xiao and P. Barker, Semiconductor nanocrystal probes for human metaphase chromosomes, Nucleic Acids Res., 2004, 32(3), e28.

61 D. Ioannou, H. Tempest, B. Skinner, A. Thornhill, M. Ellis and D. Griffin, Quantum dots as new-generation fluorochromes for FISH: an appraisal, Chromosome Res., 2009, 17(4), 519-530.

62 D. Larson, W. Zipfel, R. Williams, S. Clark, M. Bruchez, F. Wise, et al. Water-soluble quantum dots for multiphoton fluorescence imaging in vivo, Science, 2003, 300(5624), 1434-1436.

63 A. Smith, S. Dave, S. Nie, L. True and X. Gao, Multicolor quantum dots for molecular diagnostics of cancer, Expert Rev. Mol. Diagn., 2006, 6(2), 231-244.

64 C. Chen, J. Peng, H. Xia, Q. Wu, L. Zeng, H. Xu, et al. Quantum-dot-based immunofluorescent imaging of HER2 and ER provides new insights into breast cancer heterogeneity, Nanotechnology, 2010, 21(9), 95101.

65 W. Mahmoud, A. Sukhanova, V. Oleinikov, Y. Rakovich, J. Donegan, M. Pluot, et al. Emerging applications of fluorescent nanocrystals quantum dots for micrometastases detection, Proteomics, 2010, 10(4), 700-716.

66 X. Wu, H. Liu, J. Liu, K. Haley, J. Treadway, J. Larson, et al. Immunofluorescent labeling of cancer marker Her2 and 
other cellular targets with semiconductor quantum dots, Nat. Biotechnol., 2003, 21(1), 41-46.

67 M. Howarth, K. Takao, Y. Hayashi and A. Ting, Targeting quantum dots to surface proteins in living cells with biotin ligase, Proc. Natl. Acad. Sci. U. S. A., 2005, 102(21), 7583-7588.

68 C. Chen, J. Peng, H.-S. Xia, G.-F. Yang, Q.-S. Wu, L.-D. Chen, et al. Quantum dots-based immunofluorescence technology for the quantitative determination of HER2 expression in breast cancer, Biomaterials, 2009, 30(15), 2912-2918.

69 C. Chen, H.-S. Xia, Y.-P. Gong, J. Peng, C.-W. Peng, M.-B. Hu, et al. The quantitative detection of total HER2 load by quantum dots and the identification of a new subtype of breast cancer with different 5-year prognosis, Biomaterials, 2010, 31(33), 8818-8825.

70 A. Generalova, S. Sizova, T. Zdobnova, M. Zarifullina, M. Artemyev, A. Baranov, et al. Submicron polymer particles containing fluorescent semiconductor nanocrystals CdSe/ ZnS for bioassays, Nanomedicine, 2011, 6(2), 195-209.

71 B. Barat, S. Sirk, K. McCabe, J. Li, E. Lepin, R. Remenyi, et al. Cys-diabody quantum dot conjugates (immunoQdots) for cancer marker detection, Bioconjugate Chem., 2009, 20(8), 1474-1481.

72 N. Barteneva and I. Vorobjev. Quantum dots in microscopy and cytometry: immunostaining applications. 2010.

73 K. Maiti, U. Dinish, C. Fu, J.-J. Lee, K.-S. Soh, S.-W. Yun, et al. Development of biocompatible SERS nanotag with increased stability by chemisorption of reporter molecule for in vivo cancer detection, Biosens. Bioelectron., 2010, 26(2), 398-403.

74 A. Samanta, K. Maiti, K.-S. Soh, X. Liao, M. Vendrell, U. Dinish, et al. Ultrasensitive near-infrared Raman reporters for SERS-based in vivo cancer detection, Angew. Chem., Int. Ed., 2011, 50(27), 6089-6092.

75 K. L. Kelly, C. Eduardo, Z. Lin Lin and C. S. George, The Optical Properties of Metal Nanoparticles: The Influence of Size, Shape, and Dielectric Environment, J. Phys. Chem. $B, 2003,107,668-677$.

76 K. Seekell, M. Crow, S. Marinakos, J. Ostrander, A. Chilkoti and A. Wax, Hyperspectral molecular imaging of multiple receptors using immunolabeled plasmonic nanoparticles, J. Biomed. Opt., 2011, 16(11), 116003.

77 M. Crow, K. Seekell, J. Ostrander and A. Wax, Monitoring of receptor dimerization using plasmonic coupling of gold nanoparticles, ACS Nano, 2011, 5(11), 8532-8540.

78 F. Lyng, E. Ó. Faoláin, J. Conroy, A. Meade, P. Knief, B. Duffy, et al. Vibrational spectroscopy for cervical cancer pathology, from biochemical analysis to diagnostic tool, Exp. Mol. Pathol., 2007, 82, 121-129.

79 M. Porter, R. Lipert, L. Siperko, G. Wang and R. Narayanan, SERS as a bioassay platform: fundamentals, design, and applications, Chem. Soc. Rev., 2008, 37(5), 1001-1011.

80 W. Lu, S. Arumugam, D. Senapati, A. Singh, T. Arbneshi, S. Khan, et al. Multifunctional oval shaped gold nanoparticle based selective detection of breast cancer cells using two photon scattering assay, ACS Nano, 2010, 4(3), 1739-1749.
81 S. Mucelli, M. Zamuner, M. Tormen, G. Stanta and P. Ugo, Nanoelectrode ensembles as recognition platform for electrochemical immunosensors, Biosens. Bioelectron., 2008, 23(12), 1900-1903.

82 W. Lu, S. Arumugam, D. Senapati, A. Singh, T. Arbneshi, S. Khan, et al. Multifunctional oval-shaped goldnanoparticle-based selective detection of breast cancer cells using simple colorimetric and highly sensitive two-photon scattering assay, ACS Nano, 2010, 4(3), 1739-1749.

83 A. Ghazani, C. Castro, R. Gorbatov, H. Lee and $\mathrm{R}$. Weissleder. Sensitive and direct detection of circulating tumor cells by multimarker $\mu$-nuclear magnetic resonance, Neoplasia, New York, NY, 2012, vol. 14(5), pp. 388-395.

84 A. De Grand and J. Frangioni, An Operational Near-Infrared Fluorescence Imaging System Prototype for Large Animal Surgery, Technol. Cancer Res. Treat., 2003, 2(6), 1-10.

85 T. L. Doane and C. Burda, The unique role of nanoparticles in nanomedicine: imaging, drug delivery and therapy, Chem. Soc. Rev., 2012, 41(7), 2885-2911.

86 A. Prina-Mello, K. Crosbie-Staunton, G. Salas, M. del Puerto Morales and Y. Volkov, Multiparametric Toxicity Evaluation of SPIONs by High Content Screening Technique: Identification of Biocompatible Multifunctional Nanoparticles for Nanomedicine, IEEE Trans. Magn., 2013, 49(1), 377-382.

87 R. M. Sánchez-Martín, L. Alexander and M. Bradley, Multifunctionalized Biocompatible Microspheres for Sensing, Annals of the New York Academy of Sciences, 2008, p. 1130, Fluorescence Methods and Applications: Spectroscopy, Imaging, and Probes, 207-17.

88 J. T. Seil and T. J. Webster, Antimicrobial applications of nanotechnology: methods and literature, Int. J. Nanomed., 2012, 7, 2767-2781. Epub 2012/06/30.

89 S. Jain, D. G. Hirst and J. M. O'Sullivan, Gold nanoparticles as novel agents for cancer therapy, Br. J. Radiol., 2012, 85(1010), 101-113. Epub 2011/10/20.

90 K. Tiwari Dhermendra, J. Takashi and B. Jitendra, Biodistribution and toxicity assessment of intravenously injected anti-HER2 antibody conjugated CdSE/ZnS quantum dots in Wistar Rats, Int. J. Nanomed., 2011, 6, 463-475. Epub Feb 252011.

91 K. Yang, C. Zhao, Y. A. Cao, H. Tang, Y. L. Bai, H. Huang, et al. In vivo and in situ imaging of head and neck squamous cell carcinoma using near-infrared fluorescent quantum dot probes conjugated with epidermal growth factor receptor monoclonal antibodies in mice, Oncol. Rep., 2012, 27(6), 1925-1931. Epub 2012/03/02.

92 D. Movia, C. Poland, L. Tran, Y. Volkov and A. Prina-Mello. Multilayered nanoparticles for personalized medicine: translation into clinical markets, Handbook of Clinical Nanomedicine: From Bench to Bedside, Pan Stanford Publishing, 2013.

93 E. C. Dreaden, A. M. Alkilany, X. Huang, C. J. Murphy and M. A. El-Sayed, The golden age: gold nanoparticles for biomedicine, Chem. Soc. Rev., 2012, 41(7), 27402779. 
94 O. Veiseh, J. W. Gunn and M. Zhang, Design and fabrication of magnetic nanoparticles for targeted drug delivery and imaging, Adv. Drug Delivery Rev., 2010, 62(3), 284-304.

$95 \mathrm{~S}$. Hilderbrand and R. Weissleder, Near-infrared fluorescence: application to in vivo molecular imaging, Curr. Opin. Chem. Biol., 2010, 14(1), 71-79.

96 J. Escobedo, O. Rusin, S. Lim and R. Strongin, NIR dyes for bioimaging applications, Curr. Opin. Chem. Biol., 2010, 14(1), 64-70.

97 H. Hong, T. Gao and W. Cai, Molecular Imaging with Single-Walled Carbon Nanotubes, Nano Today, 2009, 4(3), 252-261.

98 K. Yong, I. Roy, H. Ding, E. Bergey and P. Prasad, Biocompatible near-infrared quantum dots as ultrasensitive probes for long-term in vivo imaging applications, Small, 2009, 5(17), 1997.

99 J. Gao, K. Chen, Z. Miao, G. Ren, X. Chen, S. Gambhir, et al. Affibody-based nanoprobes for HER2-expressing cell and tumor imaging, Biomaterials, 2011, 32(8), 2141-2148.

100 T. Behnke, J. Mathejczyk, R. Brehm, C. Würth, F. Gomes, C. Dullin, et al. Target-specific nanoparticles containing a broad band emissive NIR dye for the sensitive detection and characterization of tumor development, Biomaterials, 2013, 34(1), 160-170.

101 M. D. Austin, C. W. C. Warren and N. B. Sangeeta, Probing the Cytotoxicity of Semiconductor Quantum Dots, Nano Lett., 2004, 4.

102 S. Suresh and D. Arivuoli, Nanomaterials for Nonlinear Optical (NLO) Applications: a Review, Rev. Adv. Mater. Sci., 2012, 30, 243-253.

103 R. Bäumner, L. Bonacina, J. Enderlein, J. Extermann, T. Fricke-Begemann, G. Marowsky, et al. Evanescent-fieldinduced second harmonic generation by noncentrosymmetric nanoparticles, Opt. Express, 2010, 18(22), 23218-23225.

104 W. Kalender, X-ray computed tomography, Phys. Med. Biol., 2006, 51(13), 43.

105 J. Hainfeld, M. O'Connor, F. Dilmanian, D. Slatkin, D. Adams and H. Smilowitz, Micro-CT enables microlocalisation and quantification of Her2-targeted gold nanoparticles within tumour regions, Br. J. Radiol., 2011, 84(1002), 526-533.

106 Y. Liu, K. Ai and L. Lu, Nanoparticulate X-ray computed tomography contrast agents: from design validation to in vivo applications, Acc. Chem. Res., 2012, 45(10), 1817-1827.
107 Q.-Y. Cai, S. Kim, K. Choi, S. Kim, S. Byun, K. Kim, et al. Colloidal gold nanoparticles as a blood-pool contrast agent for X-ray computed tomography in mice, Invest. Radiol., 2007, 42(12), 797-806.

108 E. A. Morris, Breast cancer imaging with MRI, Radiologic Clinics of North America, 2002, 40(3), 443-466.

109 M. Lemort, A. Canizares-Perez, A. Van der Stappen and S. Kampouridis, Progress in magnetic resonance imaging of brain tumours, Curr. Opin. Oncol., 2007, 19(6), 616-622.

110 L. Sampath, S. Kwon, S. Ke, W. Wang, R. Schiff, M. Mawad, et al. Dual-labeled trastuzumab-based imaging agent for the detection of human epidermal growth factor receptor 2 overexpression in breast cancer, J. Nucl. Med., 2007, 48(9), 1501-1510.

111 S. Laurent and M. Mahmoudi, Superparamagnetic iron oxide nanoparticles: promises for diagnosis and treatment of cancer, Int. J. Mol. Epidemiol. Genet., 2011, 2(4), 367-390.

112 H.-M. Yang, C. Park, M.-A. Woo, M. Kim, Y. Jo, H. Park, et al. HER2/neu Antibody Conjugated Poly(amino acid)-Coated Iron Oxide Nanoparticles for Breast Cancer MR Imaging, Biomacromolecules, 2010, 11, 2886-2872.

113 Y. Mi, K. Li, Y. Liu, K.-Y. Pu, B. Liu and S.-S. Feng, Herceptin functionalized polyhedral oligomeric silsesquioxane conjugated oligomers - silica/iron oxide nanoparticles for tumor cell sorting and detection, Biomaterials, 2011, 32(32), 8226-8233.

114 F. Kievit, Z. Stephen, O. Veiseh, H. Arami, T. Wang, V. Lai, et al. Targeting of primary breast cancers and metastases in a transgenic mouse model using rationally designed multifunctional SPIONs, ACS Nano, 2012, 6(3), 2591-2601.

115 E. Flynn and H. Bryant, A biomagnetic system for in vivo cancer imaging, Phys. Med. Biol., 2005, 50(6), 1273-1293.

116 Magnetic Sentinel Lymph Node Detection for Breast Cancer Thirty-Third Annual CTRC-AACR San Antonio Breast Cancer Symposium, ed. L. Johnson, Q. Pankhurst, A. Purushotham, A. Brazdeikis, M. Douek, San Antonio, 2010.

117 N. Adolphi, K. Butler, D. Lovato, T. Tessier, J. Trujillo, H. Hathaway, et al. Imaging of Her2-targeted magnetic nanoparticles for breast cancer detection: comparison of SQUID-detected magnetic relaxometry and MRI, Contrast Media Mol. Imaging, 2012, 7(3), 308-319.

118 A. M. Nightingale and J. C. de Mello, Microscale synthesis of quantum dots, J. Mater. Chem., 2010, 20, 8454-8463. 